\title{
Crack initiation under thermal fatigue: An overview of CEA experience Part II (of II): Application of various criteria to biaxial thermal fatigue tests and a first proposal to improve the estimation of the thermal fatigue damage
}

\author{
A. Fissolo a,*, C. Gourdin ${ }^{a}$, O. Ancelet ${ }^{a}$, S. Amiable ${ }^{b}$, A. Demassieux ${ }^{a}$, S. Chapuliot ${ }^{\text {a }}$, N. Haddar ${ }^{c}$, F. Mermaz $^{\text {, }}$, \\ J.M. Stelmaszyk ${ }^{\mathrm{d}}$, A. Constantinescu ${ }^{\mathrm{b}}$, L. Vincent ${ }^{\mathrm{e}}$, V. Maillot $^{\mathrm{e}}$ \\ ${ }^{a}$ Commissariat à l'Energie Atomique - Saclay, Département de Modélisation de Systèmes et Structures/Service d'Etudes Mécaniques et Thermiques/Laboratoire d'Intégrité \\ des Structures et de Normalisation Bat 607, 91191 Gif sur Yvette Cédex, France \\ ${ }^{\mathrm{b}}$ Ecole Polytechnique, Laboratoire de Mécanique des Solides - CNRS UMR 7649, École Polytechnique, 91128 Palaiseau cedex, France \\ ${ }^{\mathrm{c}}$ Ecole Supérieure des Mines de Paris, Ecole Nationale d'Ingénieur de Sfax, B.P W.3038, Sfax Tunisie, Tunisia \\ ${ }^{\mathrm{d}}$ Institut de Radioprotection et de Sûreté Nucléaire, BP17 - 92262 Fontenay-aux-Roses Cedex, France \\ ${ }^{\text {e } C o m m i s s a r i a t ~ a ̀ ~ l ' E n e r g i e ~ A t o m i q u e ~-~ S a c l a y, ~ S e r v i c e ~ d e ~ R e c h e r c h e s ~ M e ́ t a l l u r g i q u e s ~ A p p l i q u e ́ e s / L a b o r a t o i r e ~ d u ~ C o m p o r t e m e n t ~ e t ~ d u ~ D o m m a g e ~ B a t ~ 455, ~}$ \\ 91191 Gif sur Yvette Cédex, France
}

A Part I accompanying paper clearly showed that for a given level of strain range $(\Delta \varepsilon)$, the number of cycles required to achieve crack initiation is significantly lower in biaxial thermal fatigue than in uniaxial isothermal fatigue.

Such discrepancy does not come from a thermal effect, as it is emphasized by a comparison between the uniaxial data, coming either from thermomechanical fatigue tests, or from isothermal low cycle fatigue tests. A detrimental effect of multiaxial loading on fatigue life is noticed in many cases as reported in the literature.

In this frame, the goal of this paper is to propose criteria in order to take into account the reduction of fatigue life resulting from the multiaxiality. Among all the examined multiaxial criteria, a criterion based on strain proposed by Zamrik, and a new criterion based on energy proposed by "Ecole Polytechnique" give the best estimations. Furthermore, application of the Zamrik's criterion using the RCC-MR method is very promising for the design engineer. Indeed, these two criteria exhibit a notable potential, since they are well adapted to all the available thermal fatigue experimental data, despite significant differences between approaches and processes developed by both accessible facilities.

However, such investigation must be continued with achievement of additional thermal fatigue tests (for higher number of cycles...), and isothermal biaxial fatigue tests.

\section{Introduction}

Thermal fatigue sometimes takes place in the cooling lines of nuclear reactor components. To estimate crack initiation damage, uniaxial isothermal fatigue curves are used [1].

The Part I accompanying paper clearly showed that for identical levels of strain, the number of cycles required to achieve crack initiation is significantly lower in thermal fatigue (ThF) than in uniaxial isothermal fatigue (LCF). This result is obtained using two distinct facilities (FAT3D and SPLASH). Only a weak thermal effect would be also evidenced for our used test conditions. So, a thermal effect would not seem to be at origin of such discrepancy. Nevertheless, to reach a definitive conclusion, a comparison with ther-

\footnotetext{
* Corresponding author. Tel.: +3316908 31 02; fax: +3316908 8784

E-mail address: antoine.fissolo@cea.fr (A. Fissolo).
}

momechanical fatigue "out of phase" tests (TMF OP) [2] is first made in the Section 2. Such comparison is useful since the TMF specimens are submitted to both uniaxial loading and temperature variation.

However, in actual components, thermal gradients $(\Delta T)$ induce biaxial mechanical loadings. In this context, the issue of a potential influence of the triaxiality factor on fatigue damage can be raised. In this respect, a current goal is to propose multiaxial criteria that are able to estimate crack initiation for austenitic stainless steels (AISI class 300) under thermal fatigue loading.

In this framework, main characteristics of thermal fatigue loading are detailed in the Section 3. So as to help with the selection of multiaxial criteria, the Section 4 deals with the investigation of the main existing criteria in the available literature. Some selected criteria were applied to CEA thermal fatigue tests in the Section 5. Since the establishment of a criterion usable by the design 


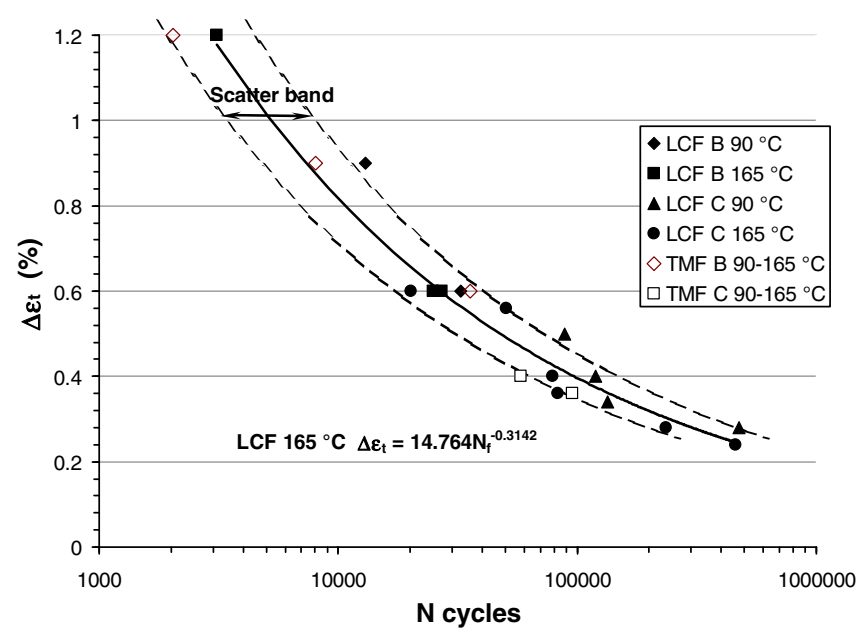

Fig. 1. Equivalent strain range as a function of the number of cycles to fatigue life obtained on both "out of phase" thermomechanical fatigue and isothermal low cycle fatigue tests. TMF specimens (open symbols) are tested for $90-165^{\circ} \mathrm{C}$, LCF specimens (full symbols) are tested for 90 and $165^{\circ} \mathrm{C}$, they are taken from two 304L steel fabrications (B and C). Equation corresponds to a $165^{\circ} \mathrm{C}$ LCF data fitting for $\Delta \varepsilon_{\mathrm{t}} \leqslant 1.2 \%$, scatter band is estimated considering a log-normal scattering for fatigue life. These results are taken from the N. Haddar's PhD (Pr. L. Remy), Ecole Nationale Supérieure des Mines de Paris.

engineer is the goal of this work, only those of the criteria easy to use on industrial components are tested. Finally, a simplified first approach to thermal fatigue is proposed in the Section 6 .

\section{Comparison between low cycle fatigue, thermomechanical fatigue and biaxial thermal fatigue}

Regarding the mechanical and thermal loading evolutions, the SPLASH and the FAT3D thermal fatigue tests (ThF tests) are comparable to the thermomechanical fatigue "out of phase" (TMF OP) tests. As for TMF OP, the SPLASH and FAT3D specimens are loaded in tension when temperature attains its minimum value (see Fig. 10 and 12, Part I).

Some TMF OP tests were performed on 304L steel at "Ecole Nationale Supérieure des Mines" under the direction of the Pr L.

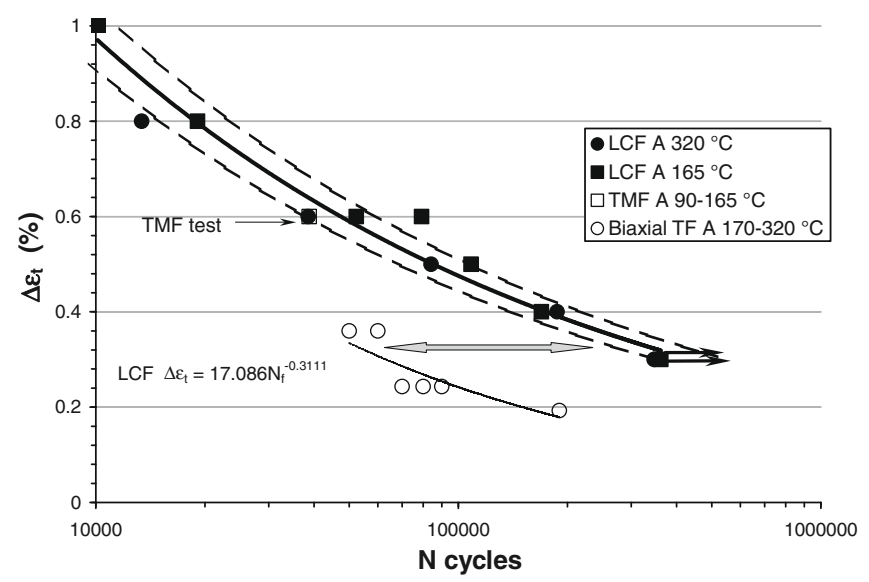

Fig. 2. Equivalent strain range as a function of the number of cycles to fatigue life obtained on one thermomechanical fatigue "out of phase" test, on isothermal low cycle fatigue, and on SPLASH biaxial thermal fatigue tests. TMF specimen (open square) is tested for $90-165^{\circ} \mathrm{C}$, LCF specimens (full symbols) are tested for 165 and $320^{\circ} \mathrm{C}$, TF SPLASH (open circle) correspond to $170-320^{\circ} \mathrm{C}$ temperature range in surface. All the specimens are taken from the same plate as used for SPLASH tests (A).

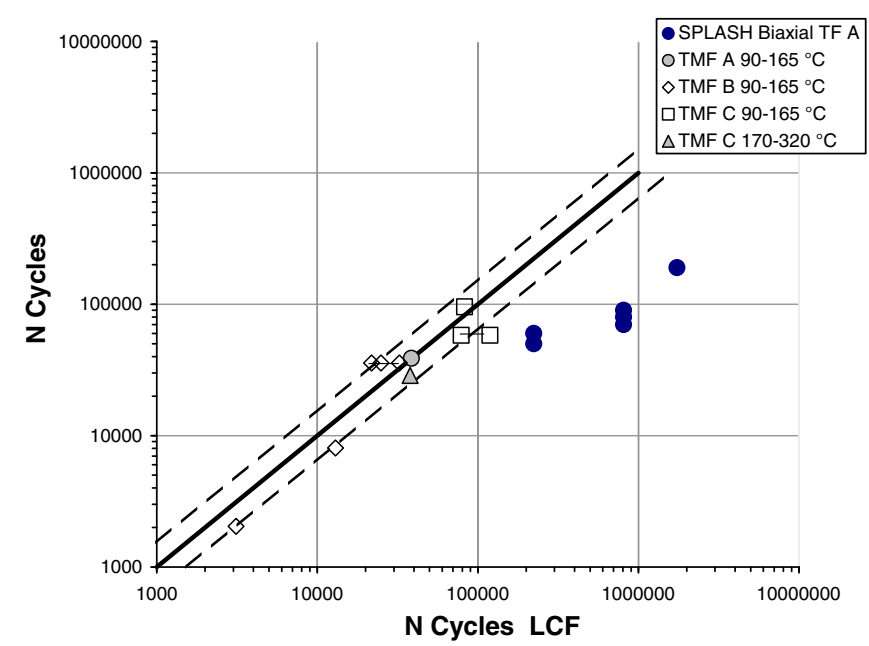

Fig. 3. Fatigue life comparison between low cycle fatigue, thermo-mechanical fatigue and biaxial thermal fatigue. Horizontal bars are linked to scattering on LCF data for identical strain range The dotted lines represent scatter band.

Remy. The temperature variation used in these tests was generally $90-165^{\circ} \mathrm{C}[3,4]$. However, one additional test was performed for $170-320^{\circ} \mathrm{C}$, which corresponds to the temperature variation for most of the SPLASH tests.

Fig. 1 compares equivalent strain range as a function of the number of cycles issued from TMF tested for $90-165{ }^{\circ} \mathrm{C}$ and LCF at 90 or $165^{\circ} \mathrm{C}$. The solid line curve represents the LCF life at $165^{\circ} \mathrm{C}$. Clearly, all the TMF points are included in the LCF scatter band (dotted curves). Results corresponding to a strain range higher than $1.2 \%$ are not taken into account, since biaxial thermal fatigue tests are only performed for $\Delta \varepsilon_{\mathrm{t}}<0.8 \%$.

Results obtained on specimens taken only from the same plate as used for SPLASH tests are gathered in Fig. 2. Regarding fatigue life for identical level of strain, we can observe:

(1) For LCF, a very slight effect of temperature between the lowest $\left(165^{\circ} \mathrm{C}\right)$ and the highest temperature $\left(320^{\circ} \mathrm{C}\right)$, generally used on the SPLASH cycle $\left(170-320^{\circ} \mathrm{C}\right)$.

(2) No difference between the one TMF OP data (open square) and the LCF data. (full symbols).

(3) In contrast, all the SPLASH biaxial thermal fatigue data (open circle) are significantly below to both TMF OP-LCF data.

In Fig. 3, the bisecting line represents the LCF life. In such way, TMF and ThF data are compared with LCF data for a given level of strain range $(\Delta \varepsilon)$. Such comparison confirms plainly the previous trend.

In conclusion, for present conditions and for a strain range below $1 \%$, we can reasonably consider that a specific thermal effect is negligible. Such result comes probably from the moderate temperature variations used in SPLASH tests. When temperature variations are significantly larger, the TMF could be more damaging than LCF, as it was shown in many investigations [5]. However, a very interesting literature investigation made by Sehitoglu [6] relates that for 304L steel, the TMF OP life is similar to the isothermal fatigue life at maximum temperature of the cycle, when temperature varies between 200 and $750{ }^{\circ} \mathrm{C}$ and plastic strain range is lower than $0.5 \%$ [7]. Let us remark that such evolution is not confirmed for the TMF "in-phase" with identical temperature variation and plastic strain. In that case, the fatigue life is significantly shorter (by nearly a factor of four), since a grain boundary sliding occurs. Furthermore, the same author [7] also relates that the TMF OP in similar conditions is more damaging than the isothermal fatigue for carbon steel. 
Although comparable TMF OP tests were not performed on $316 \mathrm{~L}$ steel, such conclusion can be reasonably extended to FAT3D tests. Yet the used strain range is always below $0.8 \%$. The 304, 316 steels have nearly similar chemical composition and metallurgical behaviour.

In consequence, we investigate now only about a detrimental multiaxiality effect. In this frame, the main characteristics of thermal fatigue loading are first presented.

\section{Main characteristics of thermal fatigue loadings}

Concerning crack initiation under thermal fatigue, one focuses on surface for two reasons. First, cracking generally appears first on the surface under fatigue. Second, stresses are maximal on the surface under thermal fatigue.

During thermal shock, most of the wall remains at the initial temperature, except for a thin surface layer (defined by the 1 and 2 directions), which undergoes a temperature variation $\Delta T$. The surface layer tends to expand in all directions by a quantity $\alpha \Delta T$, but this is prevented by the rigidity of the rest of the wall. Consequently, it is compensated by a deformation of the material in this layer. For a free wall submitted to a very local cyclic thermal shock, strain ranges are given by

$\Delta \varepsilon_{1}=\Delta \varepsilon_{2}=\alpha \Delta T$

As a result, mechanical loading is perfectly equibiaxial on the surface. Fig. 4 compares strain and stress fields resulting from thermal fatigue on the surface, to strain and stress fields resulting from classical fully-reversed torsion and push-pull tests. Relations between stresses and strains refer to Hooke's modified equations [8]. The modified Poisson's value $\bar{v}$ ranges between 0.3 for elasticity and 0.5 for full plasticity.

When loading is perfectly equibiaxial, all directions 1 and 2 located on the surface are the principal axis, and maximal shearing planes are oriented at $45^{\circ}$ to the surface. Such a mechanical state explains the completely isotropic character of the crack network formation in thermal fatigue. When plasticity is significant, compressive and tensile parts become equal. This is generally the case for austenitic stainless steels where plasticity may occur even for low loading.

The structural effect can obviously modify the mechanical state, for instance when stiffness is significantly lower along the surface (case of a narrow plate). Recall that the ratio of the principal stresses is not 1 , but $0.7-0.76$ for the SPLASH specimen.

\section{Multiaxial high cycle fatigue criterion}

Many multiaxial criteria only concern endurance limit. In this case, for the mechanical quantity used by the criterion, the task is to quantify the amount of shift resulting from multiaxiality itself. However, some of these criteria are also suitable to the limited life regime. Multiaxial criteria formulated in stresses, in strains, and in energy will be presented in successive sequence. Prior to that, the two main factors contributing to crack initiation mechanisms are briefly exposed.

In the HCF regime, investigation of the crack initiation is particularly important, since this stage (as several grain-size length cracks) could correspond to more than $90 \%$ of the total component life [9].

\subsection{Two main factors for the crack initiation mechanisms}

The shearing stress is the first main factor leading to a fatigue damage development [9-11]. Regarding the shearing stress itself, a difficulty may arise from the choice of the critical plane. One can consider either the maximum shearing stress plane corresponding to $\tau_{\max }$, or the octahedral shearing plane corresponding to $\tau_{\text {oct }}$. For an elementary defined volume, two shearing stress planes and eight octahedral stress planes can be exhibited. Crack initiation in the octahedral planes seems to be the most probable. However, in practical instances, crack initiations have been observed in the both cases depending on the material itself.

The octahedral stress amplitude is given by $[12,13]$

$$
\begin{aligned}
\left.\sqrt{\left(J_{2}\right.}\right)_{\text {alt }} & =\sqrt{(1 / 2) \underline{\underline{\sigma^{\prime}}}: \underline{\underline{\sigma^{\prime}}}} \\
& =(1 / 2) \operatorname{Max}_{t_{0} \in T} \operatorname{Max}_{t_{1} \in T} J_{2}\left(\sigma\left(t_{1}\right)\right)-\left(\sigma\left(t_{0}\right)\right)
\end{aligned}
$$

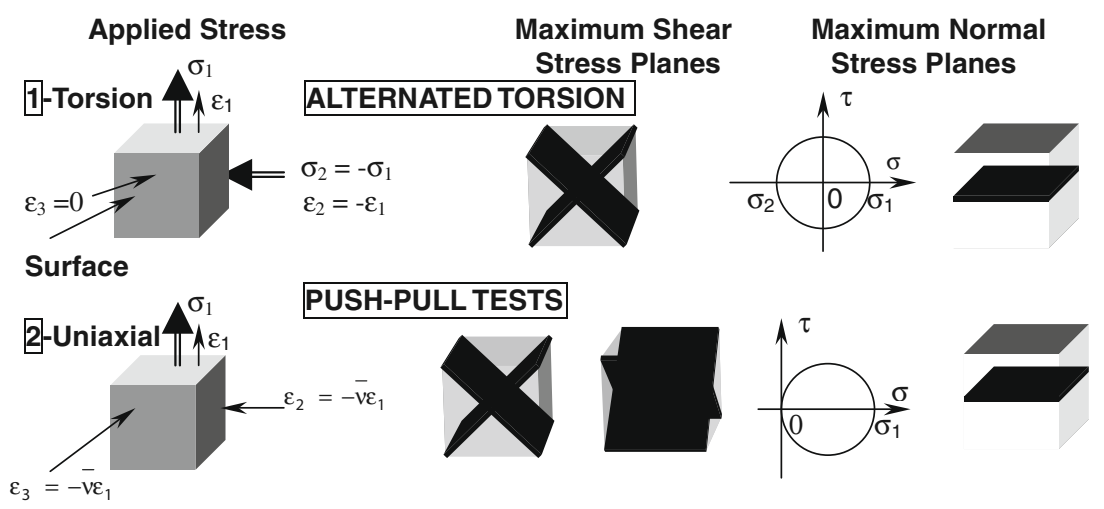

3- Perfect Biaxiality, THERMAL FATIGUE IN SURFACE FOR A FREE WALL
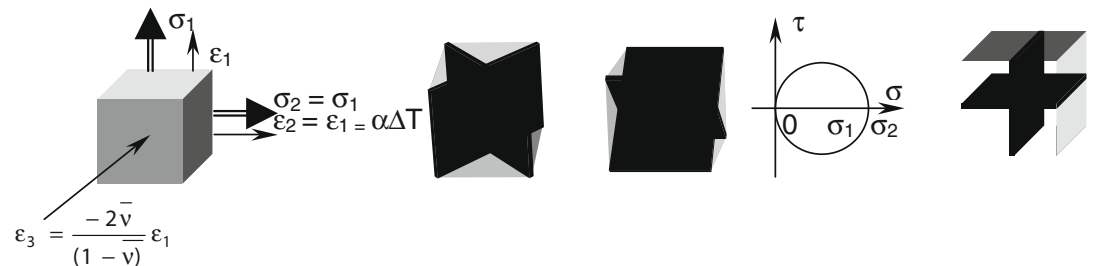

Fig. 4. Comparison of strain and stress fields for classical alternated (or fully-reversed) torsion and push-pull tests with a free wall submitted to a thermal fatigue loading 
The maximum shearing stress Tresca $\tau_{\max }$ is given by

$\sigma_{\text {eq }}^{\text {Tresca }}=2 \tau_{\max }=\operatorname{Sup}_{i \neq j}\left(\left|\sigma_{i}-\sigma_{j}\right|\right)$

The hydrostatic stress is the second main factor leading to fatigue damage. An increase in the hydrostatic stress leads to a change in the crack initiation mechanisms themselves. Low hydrostatic stresses lead to the development of shallow cracks that propagate parallel to the surface (Type A damage), whereas high hydrostatic stresses lead instead to development of stair displacements on the surface and to deeper and more damaging cracks (Type B damage). An increase in the hydrostatic stress leads also to an increase in the pressure on the crack lips, impeding crack closure during unloading (see Figs. 19 and 20 of Part I). The interesting quantities calculated for a cycle are the mean value, the amplitude, and the maximal value of the hydrostaticstress

$$
\begin{aligned}
& \sigma_{\text {mean }}^{\mathrm{H}}=\left[\max _{t \in T} \operatorname{Tr}(\sigma(t)) / 3+\min _{t \in T} \operatorname{Tr}(\sigma(t)) / 3\right] / 2 \\
& \sigma_{\text {alt }}^{\mathrm{H}}=\left[\max _{t \in T} \operatorname{Tr}(\sigma(t)) / 3+\min _{t \in T} \operatorname{Tr}(\sigma(t)) / 3\right] / 2 \\
& \sigma_{\text {max }}^{\mathrm{H}}=\sigma_{\text {mean }}^{\mathrm{H}}+\sigma_{\text {alt }}^{\mathrm{H}}
\end{aligned}
$$

\subsection{Multiaxial criteria based on stress}

\subsubsection{General remarks}

According to the explanation given before, multiaxial criteria based on stress are naturally based on shearing and hydrostatic stresses. They are generally applied for the purpose of estimating the endurance limit, assuming an elastic shakedown. However, austenitic stainless steels have the face centred cubic structure (FCC). Such crystallographic structure promotes a very easy dislocation slipping. As a result, cyclic plasticity can be observed in the endurance domain, even for low yield stresses and very high number of cycles. Although these criteria do not seem well adapted to our case, some of them have been selected, since they are widely used in industry.

Three categories can be discriminated: a first category includes empirical relations obtained from different stress state tests, a second category includes criteria based on global equivalent values, a third refers to critical plane approaches.

4.2.1.1. First category: Criterion based on empirical relations. Gough and Pollard were the first to propose a relation obtained from a large number of torsion-bending fatigue tests $[13,14]$. The relation includes loading characteristics, such as $\Sigma_{\mathrm{a}}$ which is the bending stress amplitude, and $T_{\mathrm{a}}$, which is the torsion stress amplitude. It depends on the endurance limit for alternated bending $\sigma_{\mathrm{D}-1}^{\mathrm{b}}$ and on the endurance limit for alternated torsion $\sigma_{\mathrm{D}-1}^{\mathrm{t}}$

$\left(T_{\mathrm{a}}^{2} /\left(\sigma_{\mathrm{D}-1}^{\mathrm{t}}\right)^{2}\right)+\left(\Sigma_{\mathrm{a}}^{2} /\left(\sigma_{\mathrm{D}-1}^{\mathrm{b}}\right)^{2}\right)=1$

\subsubsection{Second category: criteria based on global equivalent values}

- Von Mises and Tresca

The first set of criteria is purely based on an equivalent cyclic stress deduced by applying either Von Mises equivalent formulation, or Tresca equivalent stress. Although they were often used, they do not seem to be well adapted, since the hydrostatic stress effect is not included.

\section{- Sines' Criterion [13]}

For cyclic torsion tests, Sines remarks that endurance limit $\left(\tau_{D}\right)$ does not significantly change when a static stress is superposed.
The proposed criterion takes into account the amplitude of octahedral shearing stress $\sqrt{\left(J_{2}\right)_{\text {alt }}}$ and of the mean hydrostatic stress on cycle $\sigma_{\text {mean }}^{\mathrm{H}}$

$\sigma_{\text {Sines }}=\sqrt{\left(\mathrm{J}_{2}\right)_{\text {alt }}}+\sqrt{3}\left\lfloor\sqrt{3}\left(\tau_{\mathrm{D}} / \sigma_{\mathrm{D} 0}\right)-1\right\rfloor \sigma_{\text {mean }}^{\mathrm{H}} \leqslant \tau_{\mathrm{D}}$

where $\sigma_{\mathrm{D} 0}$ is the endurance limit for repeated tension.

To deduce $\sigma_{\mathrm{D}-1}$ from $\sigma_{\mathrm{Do}}$, a Goodman's relation can be often applied. Generally, we also have [18]: $\sigma_{\mathrm{D}-1}=\mathrm{kUTS}$ with $0.4 \leqslant \mathrm{k} \leqslant 0.6$ where UTS is the ultimate tensile strength. Finally, Sines' criterion is given by

$\sqrt{3\left(\mathrm{~J}_{2}\right)_{\mathrm{alt}}}+3 k \sigma_{\text {mean }}^{\mathrm{H}} \leqslant \sigma_{\mathrm{D}-1}$

\section{- Crossland's criterion [15,17-19]}

For the hydrostatic stress, the maximum value during the cycle is considered instead of the mean value. For the endurance limit, alternated tension is considered in place of repeated tension

$\sigma_{\text {Crossland }}=\sqrt{\left(J_{2}\right)_{\text {alt }}}+\sqrt{3}\left\lfloor\sqrt{3}\left(\tau_{\mathrm{D}-1} / \sigma_{\mathrm{D}-1}\right)-1\right\rfloor \sigma_{\max }^{\mathrm{H}} \leqslant \tau_{\mathrm{D}-1}$

4.2.1.3. Third category: criteria based on stress and on critical plane approaches

- Dang Van's criterion [15,20]

The most usual criterion based on a critical plane approach was proposed by Dang Van in 1973. An elastic shakedown response at the grain scale itself is a required condition to avoid a crack initiation after a high number of cycles. Starting from external loading, a cyclic macroscopic response $\sigma_{\text {macro }}(t)$ is determined when the cycle becomes stabilized. A cyclic mesoscopic response $\sigma_{\text {meso }}(t)$ is then deduced. As assumed before, the mesoscopic response $\sigma_{\text {meso }}(t)$ must verify the plasticity criteria at each time: $\forall \overrightarrow{\mathbf{n}}, \forall \mathbf{t} \in \mathbf{T}$,

$\tau_{\text {meso }}(\overrightarrow{\mathbf{n}}, \mathbf{t})+a \sigma_{\text {meso }}^{\mathrm{H}}(\mathbf{t})<b$

$a$ and $b$ are material parameters, $\tau_{\text {meso }}(\overrightarrow{\mathbf{n}}, \mathbf{t})$ and $\sigma_{\text {meso }}^{\mathrm{H}}(\mathrm{t})$ are the shearing and the hydrostatic mesoscopic stresses as a function of time, respectively.

For a periodic macroscopic loading and an elastic shakedown, it is proposed

$\forall \mathbf{t} \in \mathbf{T}, \sigma_{\text {meso }}^{\mathrm{H}}(\mathbf{t})=\sigma_{\text {macro }}^{\mathrm{H}}(\mathbf{t})$

Calculation of $\tau_{\text {meso }}(\overrightarrow{\mathbf{n}}, \mathbf{t})$ is not evident for the general case. However, for alternated proportional loadings, shearing mesoscopic stresses and shearing macroscopic stresses are equal. Eq. (7) can be also expressed as

$\operatorname{Max}_{\vec{n}}\left[\operatorname{Max}_{t}\left[\tau_{\text {meso }}(\overrightarrow{\mathbf{n}}, \mathbf{t})\right]\right]+\operatorname{Max}\left[\underset{t}{a} \sigma^{\mathrm{H}}(t)\right]<b$

The material constants $a$ and $b$ may be calculated from two very usual cycling loading as fully-reversed torsion and push-pull test.

Papadopoulos [21] extends this criterion. At the mesocopic scale, it uses a kinematic and isotropic behaviour with a Von Mises plasticity criterion.

\section{- Matake's criterion [22]}

The critical plane is the highest shearing stress plane. The normal stress to that critical plane is considered in place of the hydrostatic stress

$\tau_{\mathrm{alt}, \mathrm{cr}}+\mathrm{k} \sigma_{\mathrm{n}, \mathrm{cr}} \leqslant \lambda$

where $\tau_{\mathrm{alt}, \mathrm{cr}}$ is the amplitude of the critical shearing stress and $\sigma_{\mathrm{n}, \mathrm{cr}}$ is the normal stress to the critical plane. 
That criterion has a form that is equivalent to the one proposed previously by Findley [23]. But, in that case, the critical plane corresponds to the maximum of the combination of both shearing stress and hydrostatic stress: $\max \left\{\tau_{\text {alt }}+k \sigma_{\mathrm{n}}\right\}$.

\section{- Mc Diarmid's criterion [24]}

As observed on specimens, Type A and Type B of cracks are considered (see Fig. 19 of Part I). Damage mechanisms strongly depend on loading, since only Type A cracks appear under torsion, whereas both Types A and B appear under tension, and only Type B appear with perfect equibiaxial loading.

The critical plane is the highest shearing stress plane and the criterion is expressed by

$\tau_{\mathrm{alt}, \mathrm{cr}}+\left(\tau_{\mathrm{D}-1}^{\mathrm{A}, \mathrm{B}} / 2 \mathrm{UTS}\right) \sigma_{\mathrm{n}, \mathrm{cr}} \leqslant \tau_{\mathrm{D}-1}^{\mathrm{A}, \mathrm{B}}$

Shearing stress limit $\tau_{\mathrm{D}-1}^{\mathrm{A}}$ or $\tau_{\mathrm{D}-1}^{\mathrm{B}}$ is used whether critical plane conducts to a Type A or a Type B crack.

\subsection{Multiaxial criteria based on strain}

\subsubsection{General remarks}

Strain approaches are less numerous than stress approaches. As constant strain-amplitude control tests are generally performed in the low cycle regime, life predictions start from the Manson-Coffin-Basquin curve established for push-pull tests [25-27]

$\Delta \varepsilon^{\mathrm{t}} / 2=\Delta \varepsilon^{\mathrm{e}} / 2+\Delta \varepsilon^{\mathrm{p}} / 2=\left(\sigma_{\mathrm{f}}^{\prime} / E\right)\left(2 N_{\mathrm{f}}\right)^{\mathrm{b}}+\varepsilon_{\mathrm{f}}^{\prime}\left(2 N_{\mathrm{f}}\right)^{\mathrm{c}}$

In the case of multiaxial loadings, the term $\Delta \varepsilon^{t} / 2$ is changed by $\Delta \varepsilon_{\mathrm{n}} / 2$, the strain amplitude that is normal to the critical plane

$\Delta \varepsilon_{\mathrm{n}} / 2=\left(\sigma_{\mathrm{f}}^{\prime} / E\right)\left(2 N_{\mathrm{f}}\right)^{\mathrm{b}}+\varepsilon_{\mathrm{f}}^{\prime}\left(2 N_{\mathrm{f}}\right)^{\mathrm{c}}$

This approach is particularly well adapted to LCF. It cannot predict an endurance limit. In spite of this, such strain approaches could be interesting in our case, since an elastic shakedown is not observed even at the endurance limit level for austenitic stainless steels.

Two categories can be discriminated: a first category includes criteria based on the sum of elastic and plastic equivalent strains modified by introducing a triaxiality factor TF, and a second one refers to critical plane approaches.

Note that all the criteria presented here are established only from traction-torsion path loadings, whereas thermal fatigue corresponds to (or is close to) a perfect equibiaxial state.

4.3.1.1. First category: criteria including a triaxiality factor. The triaxiality factor TF [28] represents the ratio between the first stress tensor invariant and the Von Mises equivalent stress

$\mathrm{TF}=\mathrm{I}_{1} / \sigma_{\mathrm{eq}}^{\mathrm{VM}}=\operatorname{Tr}(\sigma) / \sigma_{\mathrm{eq}}^{\mathrm{VM}}=3 \sigma_{\mathrm{H}} / \sigma_{\mathrm{eq}}^{\mathrm{VM}}$

\section{- Manson-Halford's criterion [29]}

The Von Mises equivalent strain is partitioned in an elastic part and a plastic part. The elastic part is unchanged, whereas the plastic part is modified by introducing a coefficient MF depending on the triaxiality factor so that

$\Delta \varepsilon_{\mathrm{eq}}^{\mathrm{t}}=\Delta \varepsilon_{\mathrm{eq}}^{\mathrm{e}}+\Delta^{*} \varepsilon_{\mathrm{eq}}^{\mathrm{p}} \quad$ with $\quad \Delta^{*} \varepsilon_{\mathrm{eq}}^{\mathrm{p}}=\operatorname{MF} \Delta \varepsilon_{\mathrm{eq}}^{\mathrm{p}}$

$\mathrm{MF}=\mathrm{TF}$ when $\mathrm{TF} \geqslant 1$ and $\mathrm{MF}=1 /(2-\mathrm{TF})$ for $\mathrm{TF}<1$

A perfect equibiaxial loading clearly increases the damage by amplifying the equivalent strain, since $\mathrm{MF}=2$.

\section{- Zamrik's criterion [29]}

Push-pull tests and fully reversed torsion tests are represented by a nearly bilinear evolution in a log-log diagram (Fig. 5): the two slopes correspond to the elastic and plastic regions.

The modelling is based on two hypotheses:

(1) The fatigue transition depends only on $\mathrm{TF}$, it corresponds to the intersection of the elastic and plastic strain life lines $\left(2 N_{\mathrm{ta}}, 2 N_{\mathrm{tt}}\right)$. The fatigue transition cycles $\left(N\right.$ cycles $\left.=2 N_{\mathrm{t}}\right)$ are given by

$$
\left(2 N_{\mathrm{t}}\right)_{\text {Axial }}^{\mathrm{c}-\mathrm{b}}=\sigma_{\mathrm{f}}^{\prime} \mathrm{E} / \varepsilon_{\mathrm{f}}^{\prime} \text { and }\left(2 N_{\mathrm{t}}\right)_{\text {Torsion }}^{\mathrm{c}_{0}-\mathrm{b}_{0}}=\left(3 / 2\left(1+v_{\mathrm{e}}\right)\right)\left(\tau_{\mathrm{f}}^{\prime} / \gamma_{\mathrm{f}}^{\prime} \mathrm{G}\right)
$$

By dividing these two expressions, the parameter $Z$ is deduced $Z=\left(2 N_{\mathrm{t} \text { Torsion }}\right)_{\text {Torsion }}^{\mathrm{c}_{0}-\mathrm{b}_{0}} /\left(2 N_{\mathrm{tAxial}}\right)_{\text {Axial }}^{\mathrm{c}-\mathrm{b}}=\left(3 / 2\left(1+v_{\mathrm{e}}\right)\right)\left(\tau_{\mathrm{f}}^{\prime} \mathrm{E} \gamma_{\mathrm{f}}^{\prime} / \sigma_{\mathrm{f}}^{\prime} \mathrm{G} \varepsilon_{\mathrm{f}}^{\prime}\right)$

For elastic strain amplitude, it proposes thus a relationship, which takes into account of TF

$\Delta \varepsilon_{\mathrm{eq}}^{\mathrm{e}}=\mathrm{Z}^{1-\mathrm{TF}}\left(\sigma_{\mathrm{f}}^{\prime} / \mathrm{E}\right)\left(2 N_{\mathrm{f}}\right)^{-\mathrm{b}}$

(2) The evolutions versus TF are identical for the equivalent plastic strain amplitude under low cycle multiaxial fatigue, and the ductility as a reduction of section under monotonic loading. Regarding ductility, Majoine [30] shows a correlation expressed as: $2^{1-\mathrm{TF}}$ when $0 \leqslant \mathrm{TF} \leqslant 6$. Therefore, evolution under multiaxial fatigue is given by

$$
\Delta \varepsilon_{\mathrm{eq}}^{\mathrm{p}}(\mathrm{TF})=\left(\Lambda^{1-\mathrm{TF}}\right) \varepsilon_{\mathrm{f}}^{\prime} \text { with } \Lambda \approx 2
$$

In the general case, equivalent total strain is then given by

$$
\Delta^{*} \varepsilon_{\mathrm{eq}}^{\mathrm{t}}=\left(Z^{\mathrm{TF}-1}\right) \Delta \varepsilon_{\mathrm{eq}}^{\mathrm{e}}+\left(\Lambda^{\mathrm{TF}-1}\right) \Delta \varepsilon_{\mathrm{eq}}^{\mathrm{p}}
$$

For $316 \mathrm{~L}$ austenitic stainless steel tested at $621^{\circ} \mathrm{C}$, values are: $Z=1.42$ and $\Lambda=2$ [29]. Zamrik's criterion also provides a good estimation for traction and torsion of Haynes 188 alloy (cobalt base) tested at $760{ }^{\circ} \mathrm{C}$.

4.3.1.2. Second category: Criteria based on strain and on critical plane approaches

- Kandil, Brown and Miller's criterion [31]

They propose a formulation derived from physical mechanisms of strain development and cracking propagation. It is assumed that

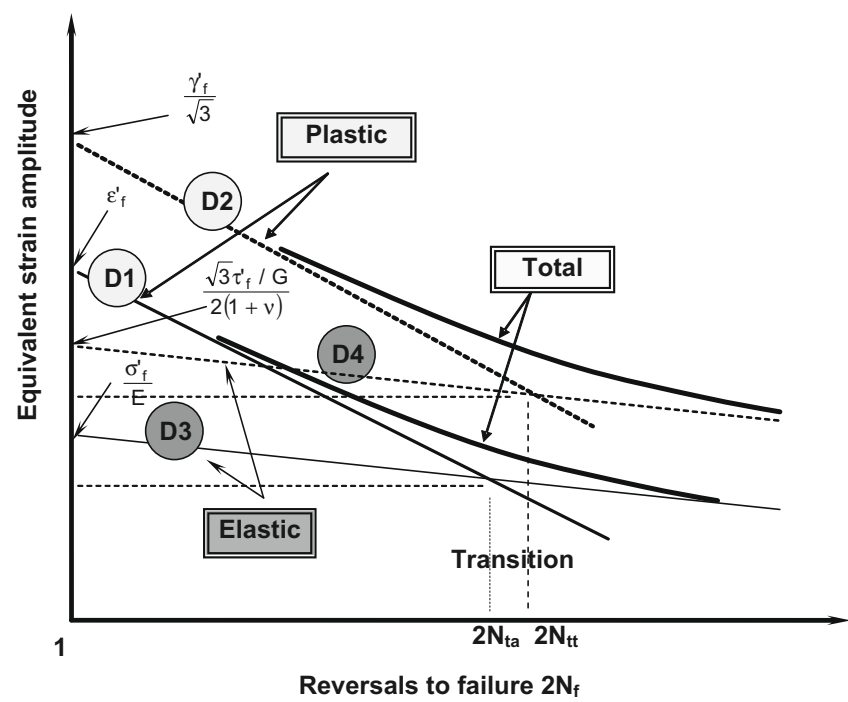

Fig. 5. Methodology of the Zamrik's criterion. Lines D1 and D3 represent push-pull tests, axial loading: D1 and D3 are plastic and elastic, respectively. Lines D2 and D4 represent repeated, torsion: D2 and D4 are plastic and elastic repectively. 
maximum shearing strain is the factor leading to plasticity process and crack initiation

$\varepsilon_{\mathrm{KBM}}=\gamma_{\max }+\mathrm{S} \varepsilon_{\mathrm{n}}=\mathrm{C}$

where $\gamma_{\max }=\gamma_{\text {mean }}+\gamma_{\text {alt }}^{\max }$ and $\gamma_{\text {alt }}^{\max }=(1 / 2) \max _{\text {to } \in \mathrm{T}} \max _{t 1 \in \mathrm{T}}\left(\varepsilon\left(t_{1}\right)-\varepsilon\left(t_{0}\right)\right)$ is the amplitude of the maximum strain shearing strain for the cycle $t$ and the chosen critical plane, $\varepsilon_{\mathrm{n}}$ is the normal strain to the shearing plane, $S$ is a material parameter.

\section{- Socie's criterion [32]}

The formulation is derived from the KBM's criterion, with an additional term depending on principal normal stress

$\varepsilon_{\text {Socie }}=\gamma_{\max }^{\mathrm{p}}+\varepsilon_{\mathrm{n}}^{\mathrm{p}}+\left(\sigma_{\mathrm{n}, \text { mean }} / E\right)=\mathrm{C}$

where $\sigma_{n, \text { mean }}=\left(\sigma_{n, \text { max }}+\sigma_{n, \text { min }}\right) / 2$ is taken in the critical plane

\section{- Fatemi and Socie's criterion [33]}

The proposed relation is again derived from the KBM's criterion. However, the normal strain is changed by a stress ratio as follows:

$\gamma_{\max }\left(1+\left(\mathrm{k} \sigma_{\mathrm{n}}^{\max } / \sigma_{\mathrm{y}}\right)\right)=\mathrm{C}$

Such a criterion has been successfully applied to a low alloy carbon steel and for Inconel 718 under traction torsion loading in and out of phase.

\subsection{Multiaxial criteria based on energy}

4.4.1. Criterion deduced from the amount of plastic distortion strain energy [34,35]

This criterion has been successfully applied in some areas such as the automotive industry [41]. However, it is not adapted to many other cases, since it is completely independent of the triaxiality factor. It is given by

$\Delta W_{\mathrm{p}}=\int_{\text {cycle }} \underline{\underline{\sigma}}: \underline{\underline{\varepsilon_{\mathrm{p}}}} \mathrm{d} t \quad\left(\right.$ or $\left.\int_{\text {cycle }} \underline{\underline{\sigma^{\mathrm{d}}}}: \underline{\underline{\varepsilon_{\mathrm{p}}}} \mathrm{d} t\right)$

4.4.2. Criteria based on shape change and volume change energy

Criteria based on energy are often a combination of volume change energy (hydrostatic part) and of shape change energy (deviatoric part). Strain energy under cyclic loading $W_{\text {cyclic }}$ can be classified into two kinds [34]: variable and static (or mean) strain energy terms, $\Delta W$ and $W_{\text {mean }}$ as:

$W_{\text {cyclic }}=\Delta W+W_{\text {mean }}$

The total variable strain energy per cycle $\Delta W$ is given by

$\Delta W=\Delta W_{\mathrm{p}}^{\mathrm{d}}+\Delta W_{\mathrm{e}}^{\mathrm{d}}+\Delta W^{\mathrm{h}}$

$\Delta W_{\mathrm{p}}^{\mathrm{d}}$ is the amount of plastic distortion strain energy (or plastic work).

\section{- Park and Nelson's criterion $[34,36]$}

Two terms related to the triaxiality factor for stress state are introduced here. A first term is the tiaxiality factor calculated for mean stress. A second term is the triaxiality factor calculated for stress amplitude. They are, respectively given by

$$
\begin{aligned}
\mathrm{TF}_{\mathrm{m}} & =\left(\sigma_{\mathrm{I}}+\sigma_{\mathrm{II}}+\sigma_{\mathrm{III}}\right)_{\mathrm{m}} / \sigma_{\mathrm{eq}}^{\mathrm{VM}} \text { and } \mathrm{TF}_{\mathrm{s}} \\
& =\left(\sigma_{\mathrm{I}}+\sigma_{\mathrm{II}}+\sigma_{\mathrm{III}}\right)_{\mathrm{a}} / \sigma_{\mathrm{eq}}^{\mathrm{VM}}
\end{aligned}
$$

where $\sigma_{\mathrm{I}}, \sigma_{\mathrm{II}}, \sigma_{\mathrm{III}}$ are principal stresses and the subscripts "m" and "a" refer to mean stress and stress amplitude. In the event of nonproportional loadings, the denominator becomes: $\sqrt{\left((3 / 8) \Delta s_{-} \mathrm{ij}^{2}\right)}$, $\Delta s_{\mathrm{ij}}$ are the components of the deviator stress amplitude.New terms $W_{\mathrm{e}}^{*}$ and $W_{\mathrm{p}}^{*}$ are calculated as a function of $T_{\mathrm{Fm}}$ and $T_{\mathrm{Fs}}$. The effective total strain energy density must be independent from the loading path:

$W_{\mathrm{t}}^{*}=W_{\mathrm{e}}^{*}+W_{\mathrm{p}}^{*}$ with $W_{\mathrm{e}}^{*}=2^{\mathrm{k}_{2} \mathrm{TF}_{\mathrm{m}}} W_{\mathrm{e}}^{\mathrm{d}}$ and $W_{\mathrm{p}}^{*}=2^{\mathrm{k}_{1}\left(\mathrm{TF}_{\mathrm{s}}-1\right)} W_{\mathrm{p}}^{\mathrm{d}}$

- The term $k_{1}$ can be determined from two tests performed with different triaxiality factors, such as alternated traction and alternated perfect biaxial traction.

- The term $k_{2}$ can be determined from evaluations of $W_{\mathrm{e}}^{*}$ for uniaxial tests performed with different mean stresses, such as fullyreversed tension $(R=-1)$ and repeated tension $(R=0)$, using for instance a Goodman's relationship.

It was also applied successfully for bending, combined bending, torsion and perfect biaxial tests with some phase shift values for mild steel and Inconel 718 [34].

- Criterion proposed by "Ecole Polytechnique" PhD S. Amiable [3739]:

Some difficulties could arise from the determination of parameters $k_{1}$ and $k_{2}$ with the Park and Nelson's criterion [34]. In this framework, a new criterion based on strain energy density has been proposed by [37-39]. The stress triaxiality is effectively taking into account, but without introducing the triaxiality factor TF explicitly. The fatigue parameter is simply defined from the amount of plastic distortion strain energy and the maximum value of the hydrostatic stress during the stabilized cycle

$W^{*}=W_{\mathrm{p}}+\alpha \sigma_{\max }^{\mathrm{H}}$

$\alpha$ is a material parameter without dimension, and $\sigma_{\max }^{\mathrm{H}}=\max \sigma^{\mathrm{H}}(t)$. It can be identified from two tests performed for different triaxiality stress states. Note that such a criterion is compatible with an endurance limit, since, for fully-reversed traction:

When $N \rightarrow \infty, W^{*} \rightarrow \alpha \sigma_{\mathrm{D}-1} / 3$ where $\sigma_{\mathrm{D}-1}$ is the endurance limit for $R=-1$.

\subsubsection{Criteria based on stress and strain on a critical plane}

- Smith, Watson, Topper's criterion (SWT) [40]:

Such a criterion was defined from the highest principal stresses and strains. Thus, it is not adapted to the cases where propagation occurs by a shearing process. Moreover, this criterion does not take the mean stress into account

$W_{\mathrm{SWT}}=\sigma_{\mathrm{n}}^{\max } \Delta \varepsilon_{\max }$

\section{- Liu's criterion based on virtual strain energy [41]}

Such a criterion is derived from the previous one. A virtual strain energy, $\Delta W$, is defined as the product of $\Delta \varepsilon$ and $\Delta \sigma$ as

$\Delta W=\Delta \sigma \cdot \Delta \varepsilon=\mathrm{E} \Delta \varepsilon_{\mathrm{e}} \cdot\left(\Delta \varepsilon_{\mathrm{p}}+\Delta \varepsilon_{\mathrm{e}}\right)$ 
where $\Delta \sigma=E \Delta \varepsilon_{\mathrm{e}}$.

The equation has a similar form as the one proposed by Smith, Watson, Topper [40]. However, a clear distinction is introduced with the process damage mode. In tensile damage mode (mode I), the criterion is the same as with SWT. In shearing damage mode (mode II), the terms $\Delta W_{\mathrm{p}}$ and $\Delta W_{\mathrm{e}}$ are calculated from shearing stresses and strains.

- Glinka's criterion [42]:

It is proposed to add up strain energy for the normal direction and for the shearing direction taken in the critical plane. For axes 1 and 2 taken on the critical plane, we have

$W=\left(\Delta \gamma_{12} / 2\right)\left(\Delta \sigma_{12} / 2\right)+\left(\Delta \varepsilon_{22} / 2\right)\left(\Delta \sigma_{22} / 2\right)$

\section{- Varvani-Farahani's criterion [43]:}

No empirical parameters would be introduced using this criterion. It is only based on material parameters deduced from classical fatigue tests, such as cyclic traction torsion, bending. Mean stress effect is specifically included

$W^{*}=\frac{1}{\sigma_{\mathrm{f}}^{\prime} \varepsilon_{\mathrm{f}}^{\prime}} \Delta \sigma_{\mathrm{n}} \Delta \varepsilon_{\mathrm{n}}+\frac{\left(1+\sigma_{\mathrm{n}}^{\text {mean }} / \sigma_{\mathrm{f}}^{\prime}\right)}{\tau_{\mathrm{f}}^{\prime} \gamma_{\mathrm{f}}^{\prime}} \Delta \tau_{\max } \Delta\left(\frac{\gamma_{\max }}{2}\right)$

with $\sigma_{\mathrm{n}}^{\text {mean }}$ the mean stress in the normal direction to the critical plane, $\Delta \tau_{\max }$ and $\Delta \gamma_{\text {maw }}$ the maximum variations of the shearing stress and strain.

\subsubsection{Remark on criteria based on strain energy}

The physical basis of such criteria is not well established. The stocked energy, which contributes effectively to the damaging process, only accounts for a small part of the applied mechanical energy. The major portion does not contribute to damage and is dissipated by a significant material heating. Consequently, criteria based on strain energy would require analysing a quantity, which is actually ten to twenty times larger than the one truly relevant to the damage process. Therefore, such a difficulty could be overcome with an amplification factor independent of loading.

\subsection{Socie's proposition for criteria based on critical plane}

Regarding multiaxial fatigue life criteria, criteria based on stresses are mainly adapted to the HCF regime, whereas criteria based on strains are mainly adapted to the LCF regime. In this manner, criteria derived from mechanical macroscopic quantities, such as strains or stresses, would not appear to be able to cover all the domains. However, other criteria based on strain energy considerations could overcome this difficulty [37-39], [40,41]. Yet the physical pertinence of a single criterion is not easy to justify. In reality, damage mechanisms are very strongly dependent on the fatigue domain being investigated. In the LCF domain, a generalized micro-cracking occurs as early as the beginning of the lifetime. Damage evolution over the lifetime mainly corresponds to crack propagation of existing cracks. It is the multiaxialty effect on crack propagation itself that is required. On the contrary, in the HCF domain, more than $90 \%$ of the total lifetime may correspond to cracking initiation itself (Fig. 6). Therefore, knowledge of the multiaxiality effects on persistent slip band, intrusions-extrusions, and micro-cracking creation and evolution is needed in the HCF domain.

Moreover, it is crucial to underline that damage mechanisms also depend strongly on the microstructure of the material as was shown for 304L stainless steel and Inconel 718 on Fig. 6 [44].

In consequence, Socie [44], proposes to discriminate three zones (Fig. 6):

- A first region A, where shearing mechanisms are dominant. Note that such a region is completely absent for 304L stainless steel, whereas it is very large for Inconel 718 . Socie proposes the Fatemi's criterion (Eq. (16)) [33].

- A second region $B$, where cracking is still initiated with shearing mechanisms. However, a large part of fatigue life corresponds to cracking propagation in a plane, which is perpendicular to the highest principal strain and stress. The SWT criterion is proposed (Eq. (21)), [40].

- A third region $\mathrm{C}$, which corresponds to high cycle fatigue, where cracking initiation concerns a very large part of fatigue life. The Mc Diarmid's criterion is proposed (Eq. (9)), [24].

The development of such modelling seems too complex in our case, where the goal is to define a criterion that is easy to use for finite-element calculations and for industrial applications.

\section{Application to SPLASH and FAT3D thermal fatigue tests}

\subsection{Preliminary observations}

This paragraph deals only with applications to SPLASH and FAT3D tests. Some multiaxial criteria based on stress, on strain, and on energy will be applied successively. The preliminary observations are:
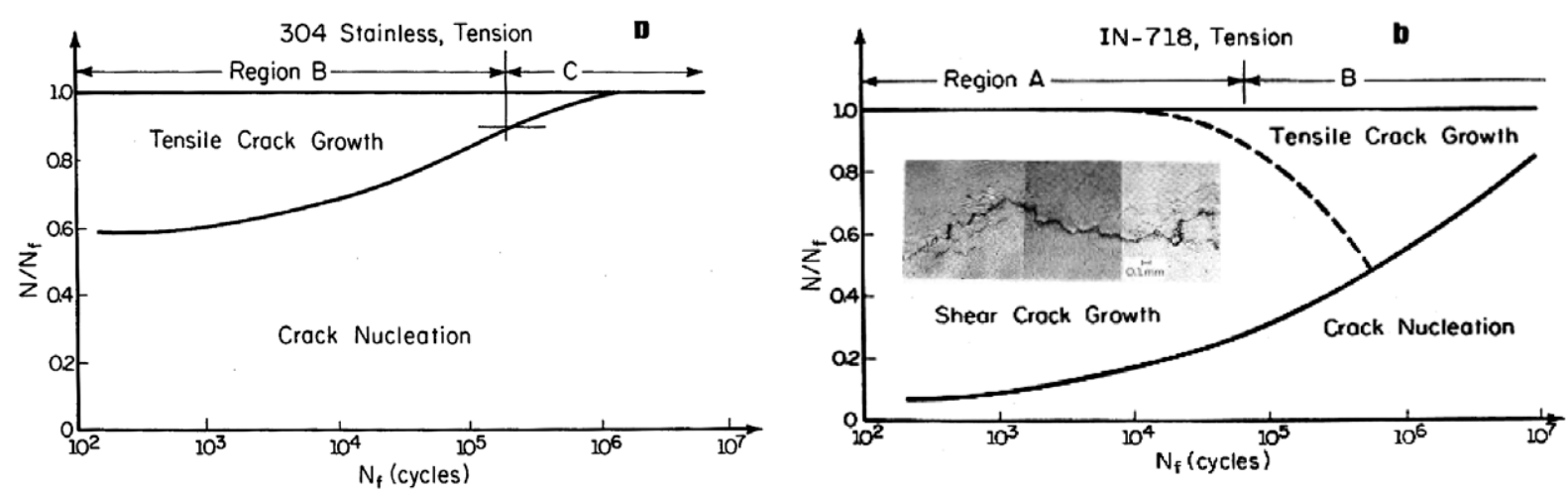

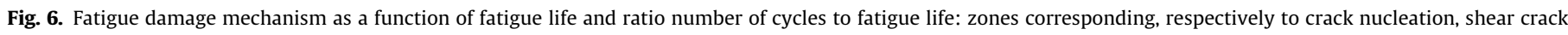
growth tensile crack growth $304 \mathrm{~L}$ austenitic stainless steel (left) and Inconel 718 (right) tested under fully reversed traction. 
(i) For identical fatigue life, strain range response is nearly comparable for both $316 \mathrm{~L}$ steel (FAT3D) and 304L steel (SPLASH), when its value is lower than $0.6 \%$ (see Appendix A for more details on LCF). Among the thermal fatigue campaigns, only one $F A T 3 D$ test corresponds to a higher strain range (FAT3D-1 0.8\%). In contrast, stabilized stress data show that $304 \mathrm{~L}$ steel has a more ductile behaviour.

(ii) Regarding triaxiality factor, all the SPLASH tests corres4pond to $\mathrm{TF}=1.95$, values of TF for FAT3D are 1.96, 1.94 and 1.86 for test $n$ are 1,2 , and 3 , respectively.

In order to investigate adequacy of each criterion, a reference curve is built by applying criterion to the uniaxial LCF data. Such curve represents the "equivalent loading" as a function of the fatigue life: it should characterize the fatigue toughness of material at all the triaxiality factors. So, the application of criterion to multiaxial fatigue data should give values close to this reference curve. The biaxial thermal fatigue data are thus compared with that one, and the deviation factor is then calculated. A large negative deviation (e.g. lower than -20\%) means an unconservative fatigue life estimation (abscissa of the fatigue graph).

\subsection{Multiaxial criteria based on stress}

Generally, they are based on fully reversed torsion data. Regarding austenitic stainless steels, we use the relation between torsion and fully reversed tension proposed by [45]

$\tau_{\mathrm{D}}=0.667 \sigma_{\mathrm{D}-1}$

As proposed by [18], we use also

$\sigma_{\mathrm{D}-1}=0.5 \mathrm{UTS}$

where UTS is the ultimate tensile strength for monotonic tensile loading.

Von Mises, Sines, Crossland and Dang Van's criteria are considered (Eqs. (2a), (5a), (5b), and (7)) [16,19,20] (Figs. 7a and b). They are applied with the stabilized stress determined at half-life.

As expected, Von Mises equivalent stress does not provide convenient estimations (Fig. 7a and b): thermal fatigue values are often far below LCF values. Exactly same trend is found with both Crossland and Sines' criteria, however deviations from low cycle fatigue curves become significantly lower. Once again, thermal fatigue appears more damaging for a same level of stress. The estimations deduced from Dang Van's criterion on FAT3D are mainly higher than LCF (Fig. 7b).

\subsection{Multiaxial criteria based on strain}

As exposed in Part I, an approach based on equivalent strain does not give good estimations (see Fig. 16 of Part I).

Manson-Halford and Zamrik's criteria [26,29] give more convenient estimations (Figs. 8a and b). Among the two, Zamrik's criterion would seem to be the best, since ThF SPLASH data are closer than LCF304L data, particularly for the highest number of cycles $\left(\Delta T=125^{\circ} \mathrm{C}\right)$, where deviation is only about $10 \%$. Deviation is larger in FAT3D, but in this case Zamrik's criterion leads ever to an equivalent strain overestimate, and to a conservative estimation of fatigue life. This latter result was longer verified by $[46,47]$.

\subsection{Multiaxial criteria based on energy}

Applied criteria are criterion based on amount of plastic distortion strain energy [35], Park and Nelson's criterion [34] and

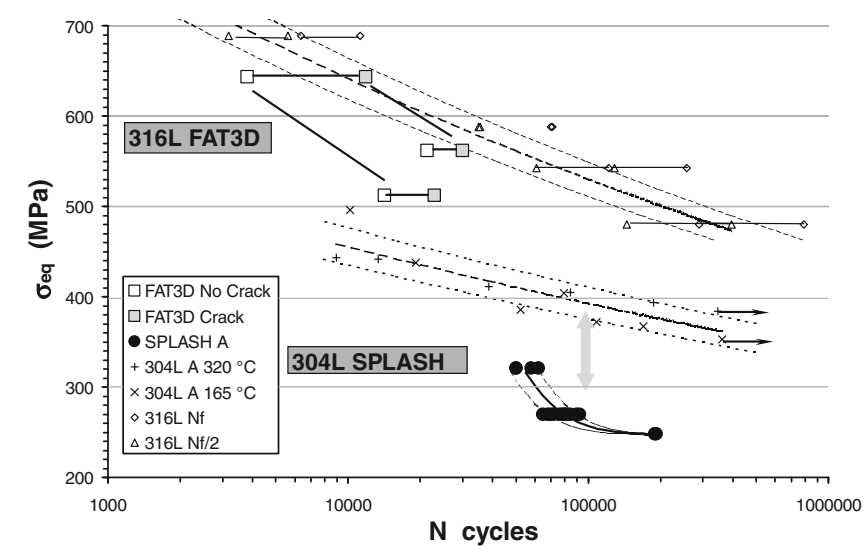

Fig. 7a. Criterion based on Von Mises equivalent stress. Scatter band is calculated for LCF tests.

Amiable's criterion ("Ecole Polytechnique") [37-39] (Figs. 9a, b and $\mathrm{c}$ ).

A criterion based on plastic distortion strain energy is also unsuitable [35] (Fig. 9c). All SPLASH data are below 304L LCF data. An improvement can be observed by applying the Park and Nelson's criterion [34] with $k_{1}=1$ and $k_{2} \approx 1,18$ (Eq. (19)) (Fig. 9a). However, it does not appear to be well adapted. The criterion proposed by S. Amiable (Eq. (20)) for SPLASH gives the best estimations for the both facilities (Figs. 9b and c). The value of $\alpha$ is also determined from traction-torsion tests [49] including thirteen loading paths (See Appendix B). We obtain: $\alpha=0.007$. As for the Zamrik's criterion, a larger deviation is observed on FAT3D, but it is mainly positive yet.

\section{Proposition of a new criterion}

The objective is to propose a suitable multiaxial fatigue criterion that is easy to use for design purposes and is also able to give good estimations. In this framework, the selected criterion is Zamrik's. It is derived from Von Mises equivalent elastic strain $\Delta \varepsilon_{\mathrm{eq}}^{\mathrm{e}}$ and equivalent plastic strain ranges $\Delta \varepsilon_{\mathrm{eq}}^{\mathrm{p}}$. In the perfect equibiaxial case

$(\mathrm{TF}=2)$, the relation is : $\Delta^{*} \varepsilon_{\mathrm{eq}}^{\mathrm{t}}=1.42 \Delta \varepsilon_{\mathrm{eq}}^{\mathrm{e}}+2 \Delta \varepsilon_{\mathrm{eq}}^{\mathrm{p}}$

In this case, an extension of the RCC-MR method [50] could be considered for applying such a criterion. The value of $\Delta \varepsilon_{\mathrm{eq}}^{\mathrm{t}}$ could be calculated after an elastic calculation, using the $K_{v}$ coefficient (see Appendix A of Part I). A table giving directly $\Delta \sigma_{\text {eq }}$ as a function of $\Delta \varepsilon_{\mathrm{eq}}^{\mathrm{t}}$ is proposed for the $316 \mathrm{~L}$ steel (A3.1S.591). Thereafter, values of $\Delta \varepsilon_{\text {eq }}^{\mathrm{e}}$ and $\Delta \varepsilon_{\mathrm{eq}}^{\mathrm{p}}$ are simply deduced. However, for 304L steel, a complete calculation of $K_{\mathrm{v}}$ coefficients must be performed (see Table 9 of Part I).

Applying the Zamrik's criterion, Fig. 10 exhibits an acceptable agreement between the estimations using loadings $\left(\Delta^{*} \varepsilon_{\mathrm{eq}}^{\mathrm{t}}\right)$ issued from the RCC-MR methodology (full square), and the estimations deduced from finite element calculations using an elasto-plastic law (full circle). Furthermore, it confirms the good agreement between LCF and ThF data (full and cross symbols), as previously observed in Figs. 8a and b. On the contrary, the present analysis, where the stress triaxiality is not taken into account, gives an important discrepancy between LCF and ThF. 

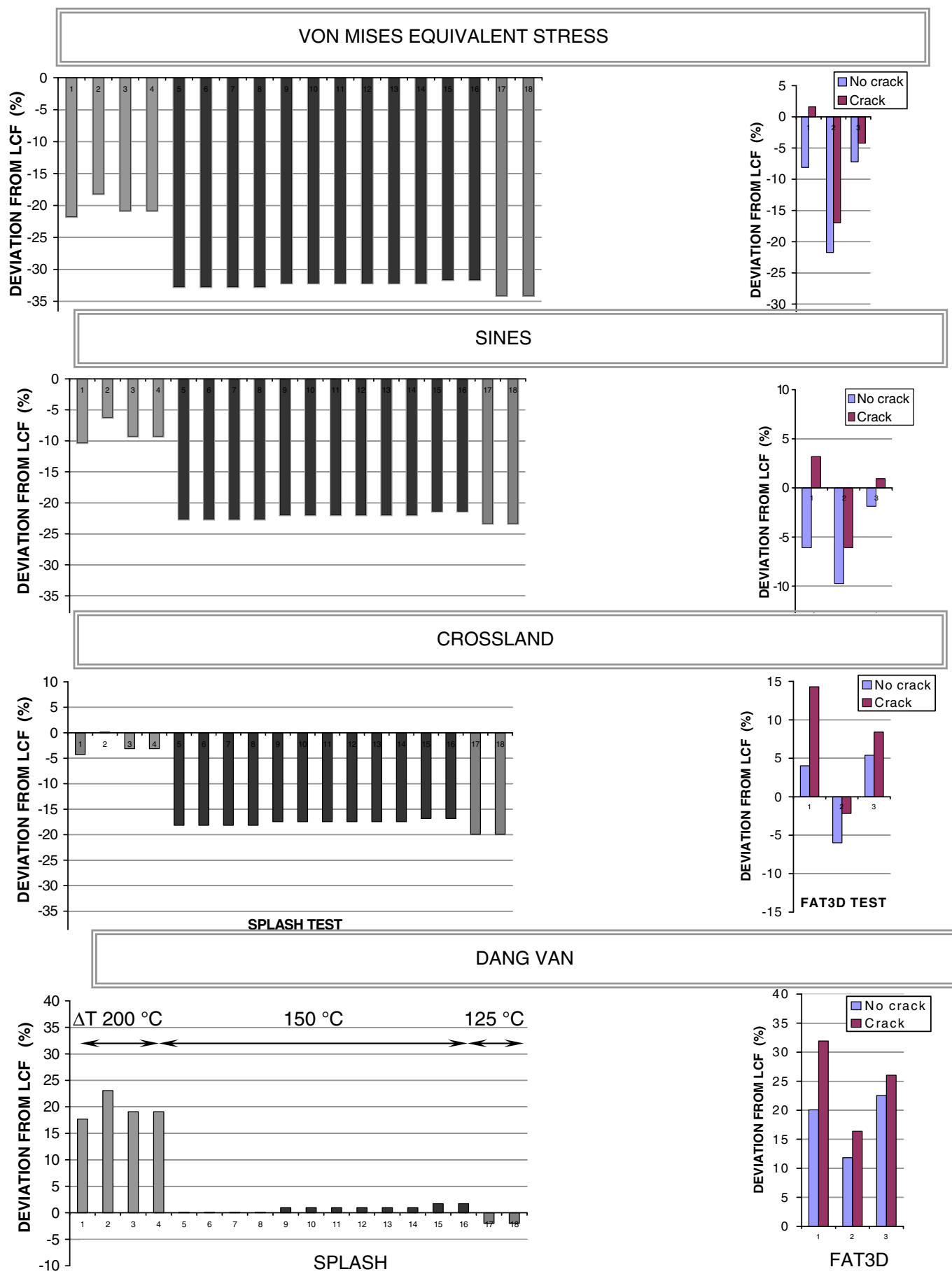

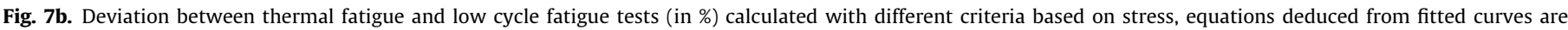
considered for low cycle fatigue. For SPLASH tests, (1-4) $\Delta T=200^{\circ} \mathrm{C}$, (516) $\Delta T=150^{\circ} \mathrm{C}$, (17 and 18) $\Delta T=125^{\circ} \mathrm{C}$.

\section{Discussion}

- Some limitations to the use of such criterion

Such criterion is verified only for pure thermal fatigue loading, proportional loading, and nearly perfect biaxial loadings. However, superimposing a mean static stress to thermal fatigue loading during cycling is possible (as pressure). A significant detrimental effect of a positive mean stress has been exhibited by [46]. In this frame- work, the available multiaxial fatigue criterion would have to be able to take additional stresses into account. This is not the case for the Zamrik's criterion, since the triaxiality factor TF does not explicitly depend on mean value. However, this could be possible with the criterion proposed by Amiable, since

$W^{*}=W_{\mathrm{p}}+\alpha \sigma_{\max }^{\mathrm{H}}=W_{\mathrm{p}}+\alpha\left(\sigma_{\text {mean }}^{\mathrm{H}}+\sigma_{\text {alt }}^{\mathrm{H}}\right)$

In any event, specific tests performed with mean stress are needed to elaborate, or to extend the validity of criteria. 


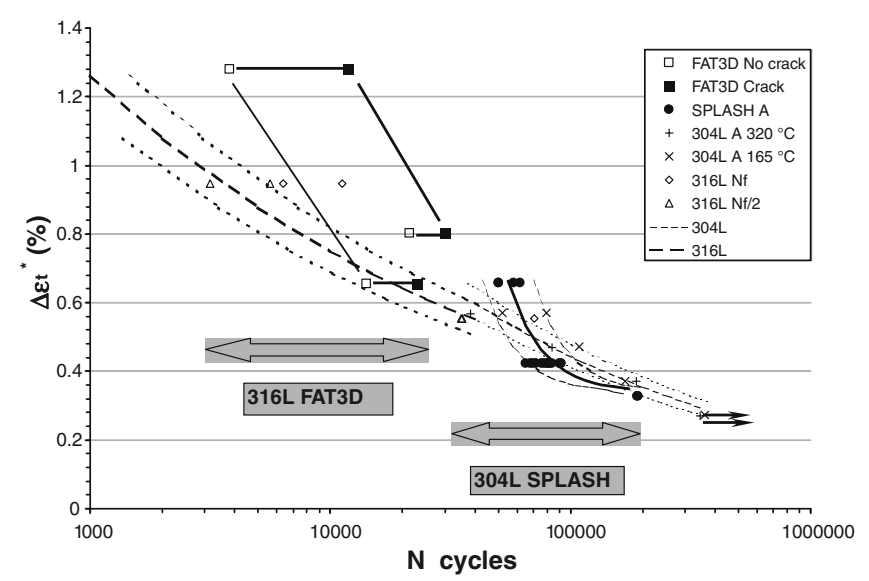

Fig. 8a. Zamriks criterion. Scatter band is calculated for LCF tests. Left side: FAT3D and LCF 316L steel. Right side: SPLASH and LCF 304L steel.

\section{- Carrying out additional tests is a necessity}

Establishing a "universal multiaxial criterion" is clearly unattainable. One can instead established criteria that are close to our material and loading path conditions: perfect equibiaxial loading for AISI Type 300 austenitic stainless steels. In that framework, performing thermal fatigue tests is a necessity. However, the number of cycles achievable does not seem to be sufficient with the present facilities, when compared with in-service conditions. The building of a new high-frequency facility would be an additional resource. Existing high-frequency facilities use either powerful-pulsed lasers [51-53], or electron beam heating [54].

Temperature measurements in the thickness may lead to some imprecision. So, a proposition is to perform also cyclic isothermal perfect biaxial tests using a special bi-traction device [55], such as the ASTREE device of "Ecole Normale Supérieure de Cachan" [56]. Let us observe that another simple tensile device is used for repeated perfect biaxial tests with the help of a special mounting adaptation [57].
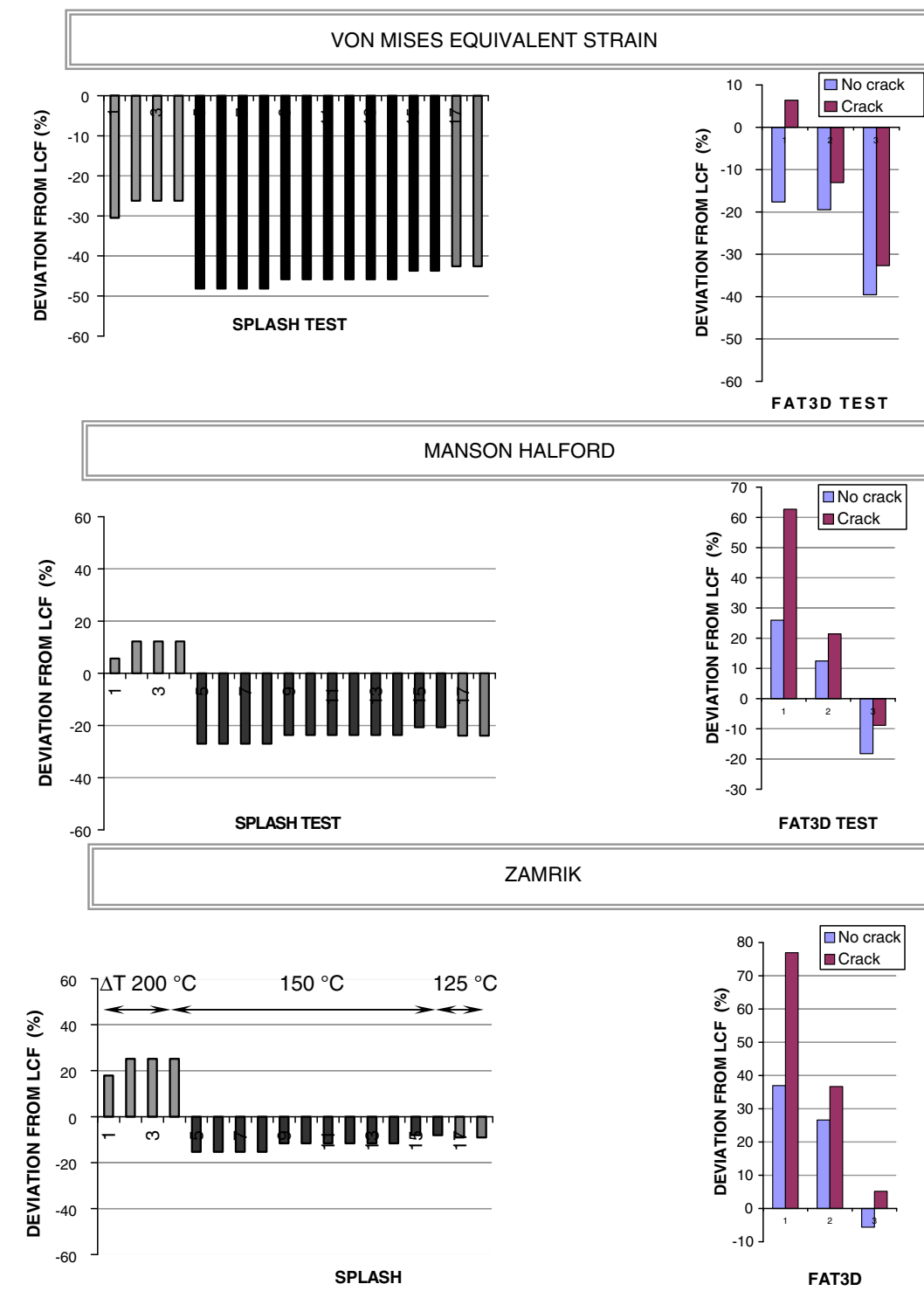

ZAMRIK

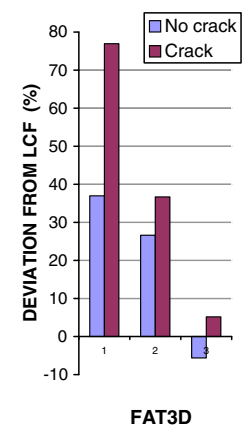

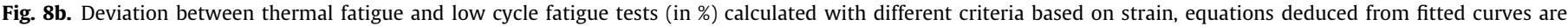
considered for low cycle fatigue. For SPLASH tests, (1-4) $\Delta T=200^{\circ} \mathrm{C}$, (516) $\Delta T=150{ }^{\circ} \mathrm{C}$, (17 and 18) $\Delta T=125^{\circ} \mathrm{C}$. 


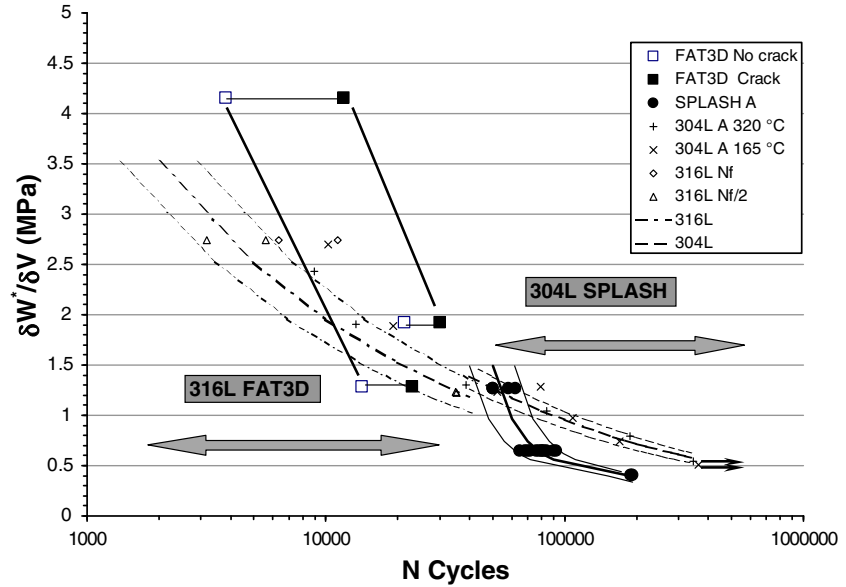

Fig. 9a. Park and Nelson's criterion. Left side: FAT3D and LCF 316L steel. Right side: SPLASH and LCF 304L steel.

\section{- Problem related to the short crack propagation}

Another question deals with the short crack propagation, because definition of the experimental crack initiation depends exclusively on the observation method. In many cases, a part of propagation can be thus included. The propagation stage is probably very limited in the case of the ThF SPLASH tests, where initiation refers to a $100-200-\mu \mathrm{m}$ crack length. However, impact of the short crack propagation stage becomes assuredly more important for the ThF FAT3D tests and also for the in-service components, where initiation refers to a 1-2-mm crack length. Besides, in the case of the isothermal reference LCF tests, $N_{25}$ (number of cycles with $25 \%$ load drop) corresponds roughly to a $2-3-\mathrm{mm}$ crack length.

As exposed already in Section 4.1 and in Section 7 of the Part I accompanying paper, it is clearly shown that a biaxial loading favours the initiation stage itself. Nevertheless, such result is strictly correct in principle, if only "microstructurally short cracks" (as cracks smaller than the grain size) are considered without no propagation. An opposite tendency is emphasized for the short crack propagation stage itself: in fact, a biaxial loading leads to a dramatic reduction of the size of the crack tip plastic zone, and of the crack tip opening displacement, which in turn would lead to a significantly lower crack propagation rate $[58,59]$. In consequence, the multiaxial loading effect on the experimental crack initiation (including some propagation) could be unobvious.

However, all the performed tests have been shown that for a given level of strain range $(\Delta \varepsilon)$, biaxial ThF data are below both uniaxial LCF and TMF data (see Figs. 1-3 and Section 2). Such evolution probably arises from a major importance of the purely crack initiation stage ("microstructurally short cracks") compared to the short crack propagation stage. Moreover, let us note also that all the presented multiaxial criteria have been generally also built from fatigue data including also some short crack propagation.

\section{- Other related problems with respect to thermal fatigue in nuclear components}

Regarding crack initiation itself, a first question deals with the surface condition. It is well known that surface roughness may be an important parameter, since machining striations can promote initiation. Residual stresses arising from machining can also promote (tension stresses), or delay (compressive stresses) initiation.

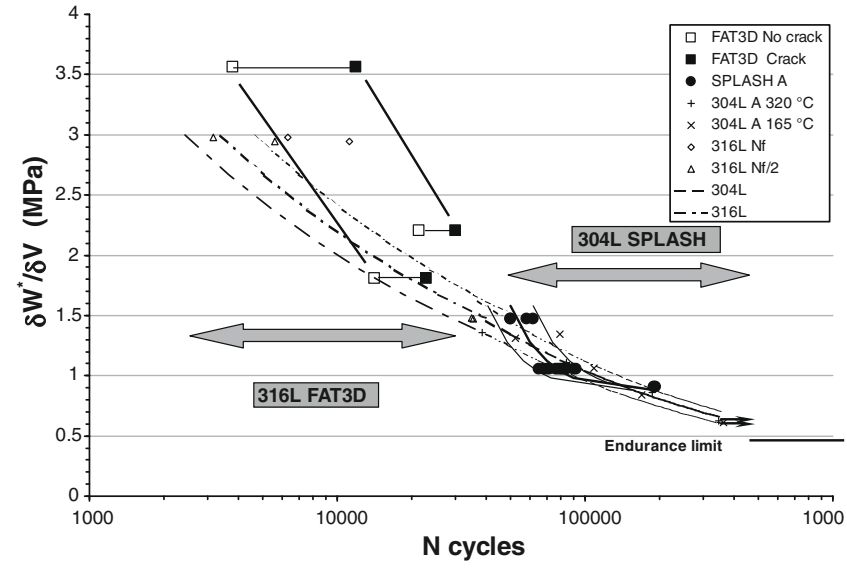

Fig. 9b. Criterion proposed by "Ecole Polytechnique" S. Amiable PhD. Left side: FAT3D and LCF 316L steel. Right side: SPLASH and LCF 304L steel.

In this framework, some investigations were carried out [60]. The interest of the shot peening process is also questioned [61].

Another problem is related to the damage summation, since inservice components are submitted to variable loadings during their life (such as variable amplitude, mean level, frequency, ...). From this perspective, first random fatigue tests have been performed at CEA with loadings that were as representative as possible. The objective was to verify the validity (or not) of the Miner's rule [62].

Although it was not investigated now in the CEA thermal fatigue programme, the environmental effect is also a damage parameter. The oxygen content for component water-cooling is very low. In this respect, results obtained on laboratory facilities would have to be conservative.

The detail investigations of RHRS components clearly show that crack propagation is also a significant problem [1], [63]. On these components, a network of thermal fatigue cracks is generally observed, with a crack propagation of up to $2.5 \mathrm{~mm}$ in depth. In this respect, the conditions for a potential crack arrest are now being investigated. Thermal loading frequency would be a very crucial parameter. Simple thermomechanical calculations show that high frequency loadings lead to a very severe attenuation of mechanical loading with depth [64]. On the contrary, low frequency thermal loadings $(\approx 0.1 \mathrm{~Hz})$ may lead to a weak attenuation. Therefore, thermal fatigue investigations require an improvement in the knowledge of thermal loadings and hydrothermal conditions, which occur in components. In pursuit of this objective, the CEA thermal fatigue programme includes tests on representative structure, such as RHRS of PWR (FATHER programme) [65].

\section{Conclusion}

1. The discrepancy between both SPLASH and FAT3D thermal fatigue and low cycle fatigue data does not come from a thermal effect. A literature investigation shows that multiaxial loadings may have a detrimental effect on fatigue life. Multiaxial criteria based on stresses, on strains, and on energy are proposed.

2. Criteria based on stress are not adapted as cyclic plasticity occurs in the endurance domain for austenitic stainless steels. The Zamrik's strain criterion proposed by $[47,48]$ and the energy criterion proposed by "Ecole Polytechnique" [37-39] provide the best estimations. 


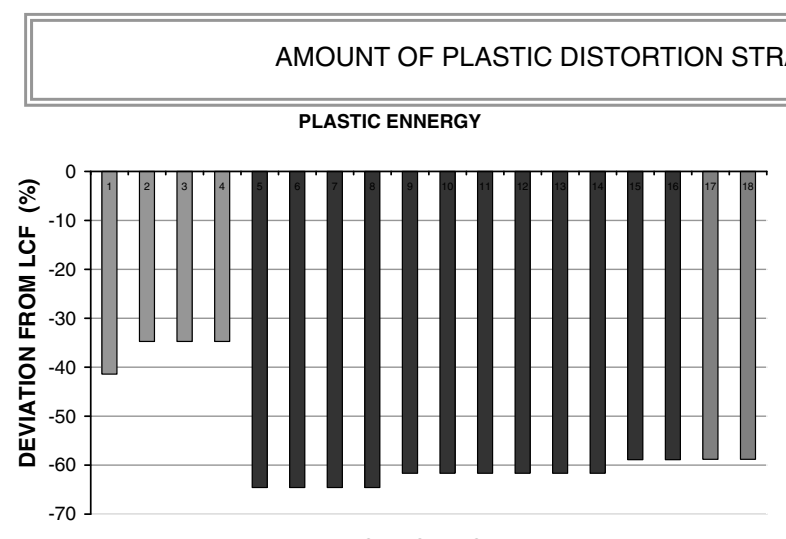

SPLASH TEST
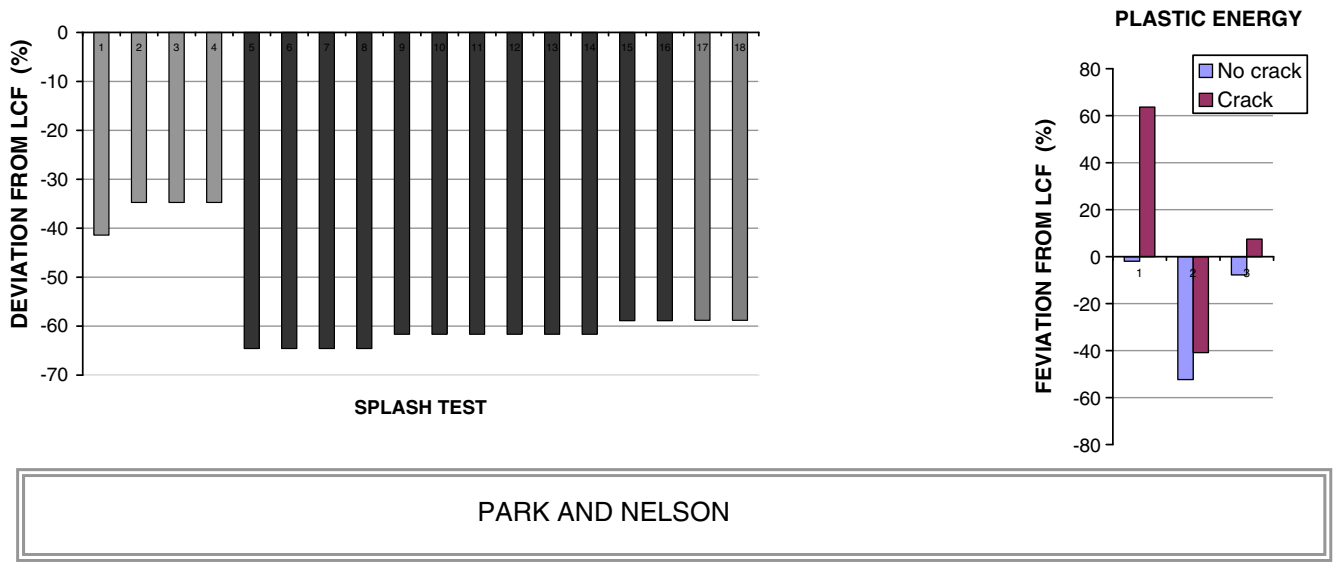

PARK AND NELSON

PARK AND NELSON

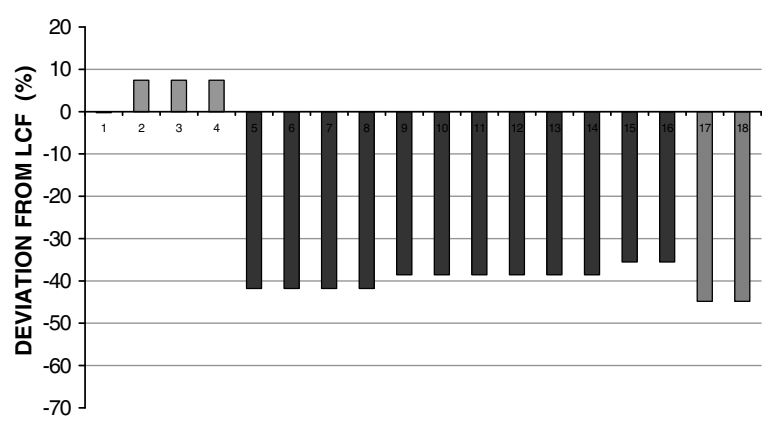

SPLASH TEST

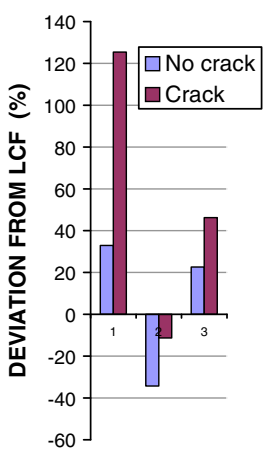

FAT3D TEST

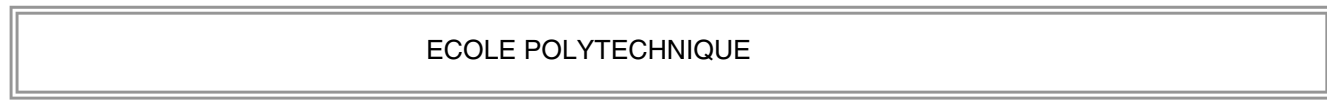

ECOLE POLYTECHNIQUE

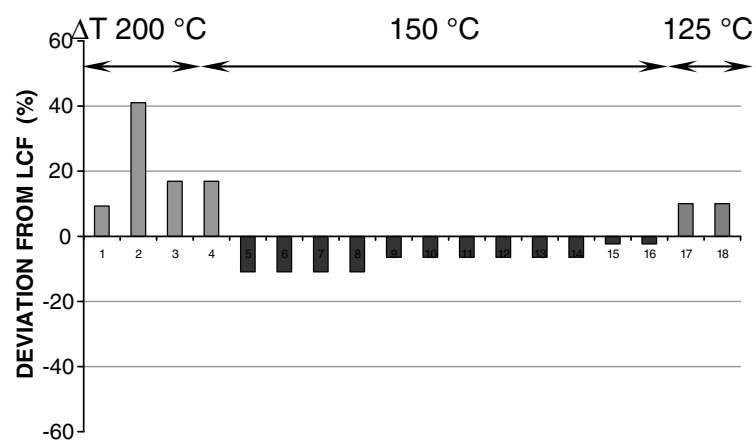

SPLASH
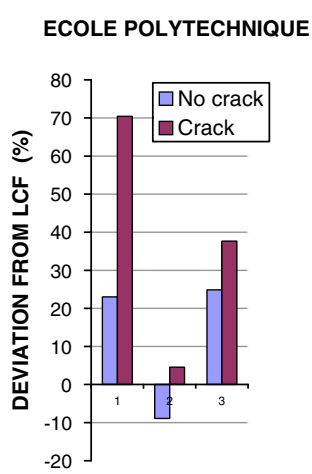

FAT3D

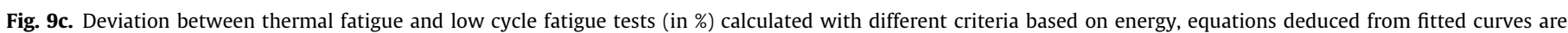
considered for low cycle fatigue. For SPLASH tests, (1-4) $\Delta T=200^{\circ} \mathrm{C}$, (516) $\Delta T=150{ }^{\circ} \mathrm{C}$, (17 and 18$) \Delta T=125^{\circ} \mathrm{C}$.

The Zamrik's strain criterion is derived from Von Mises equivalent elastic strain range $\Delta \varepsilon_{\mathrm{eq}}^{\mathrm{e}}$ and equivalent plastic strain range $\Delta \varepsilon_{\mathrm{eq}}^{\mathrm{p}}$

$\Delta^{*} \varepsilon_{\mathrm{eq}}^{\mathrm{t}}=\left(1.42^{\mathrm{TF}-1}\right) \Delta \varepsilon_{\mathrm{eq}}^{\mathrm{e}}+\left(2^{\mathrm{TF}-1}\right) \Delta \varepsilon_{\mathrm{eq}}^{\mathrm{p}}$ with $T F=3 \sigma_{\mathrm{H}} \sigma_{\mathrm{eq}}^{\mathrm{VM}}$

The energy fatigue parameter is simply defined from the dissipated energy $W p$, and the maximum value of the hydrostatic stress $\sigma_{\max }^{H}$ during the stabilized cycle

$$
\begin{aligned}
W^{*} & =W_{\mathrm{p}}+0.007 \sigma_{\max }^{\mathrm{H}} \text { with } W_{\mathrm{p}}=\int_{\text {cycle }} \underline{\underline{\sigma}}: \underline{\underline{\varepsilon}}^{\mathrm{p}} \mathrm{t} d \text { and } \sigma_{\max }^{\mathrm{H}} \\
& =\max _{\mathrm{t}} \sigma^{\mathrm{H}}(\mathrm{t}) .
\end{aligned}
$$

3. These two criteria are well adapted to both SPLASH and FAT3D tests, despite significant differences between experimental processes and approaches developed on both facilities: 


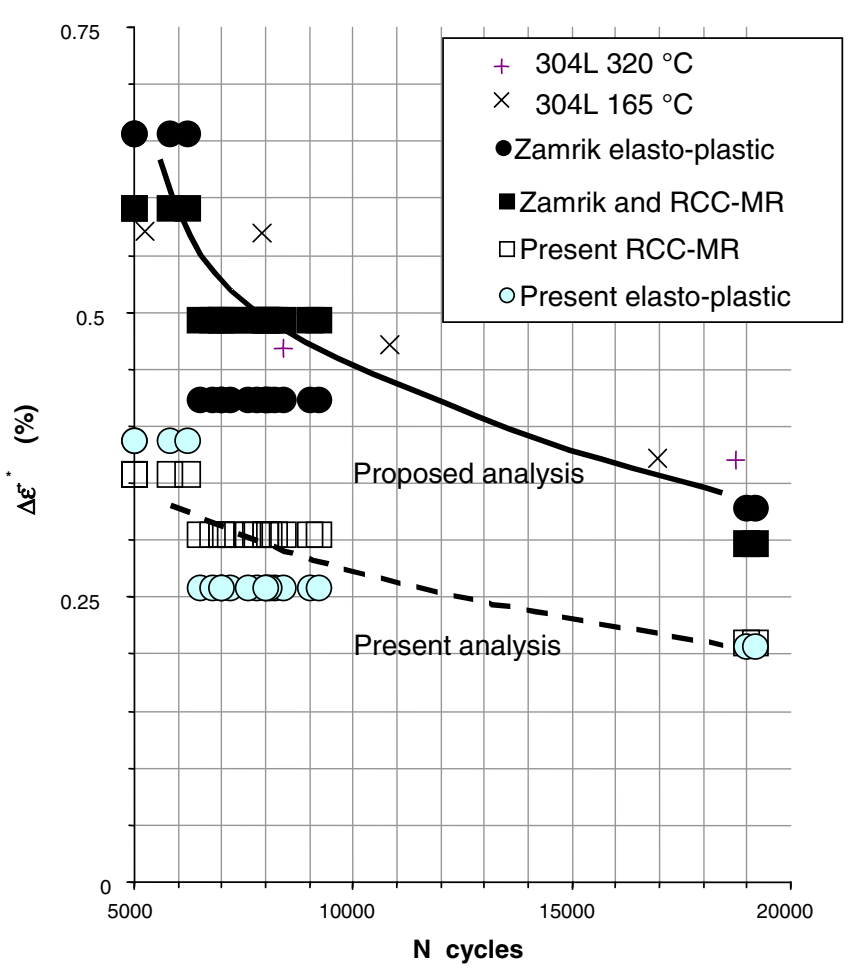

Fig. 10. SPLASH tests, comparison between the proposed analysis and the present analysis, and for the new proposed analysis, concerning the proposed analysis (full black symbols) comparison between Zamrik and RCC-MR analysis, and Zamrik and elasto-plastic calculations.

- the SPLASH specimen is a "2D specimen", since thermal fatigue results from an in-thickness temperature variation in a free plate. Crack initiation corresponds to the first crack length corresponding to one to two grain sizes.

- the FAT3D specimen is a "3D specimen", and consequently more representative of in-service components. An approach based on structural mechanics integrity is adopted to define crack initiation (1-2-mm length).

4. The Zamrik's criterion using the RCC-MR method is already quite promising, since elastic and plastic parts can be simply deduced from an elastic calculation and the amplifying factor $K_{v}$. However, some adaptations must still be made, since an endurance limit cannot be estimated.

\section{Acknowledgments}

This work was initiated and supported by the French institute of protection and nuclear safety IRSN

\section{Appendix A. Comparison between 304L and 316L steels LCF properties used for SPLASH and FAT3D data investigations, respectively}

In Fig. A1, strain range is represented as a function of the number of cycles for both 316L and 304L steels. Evolutions are

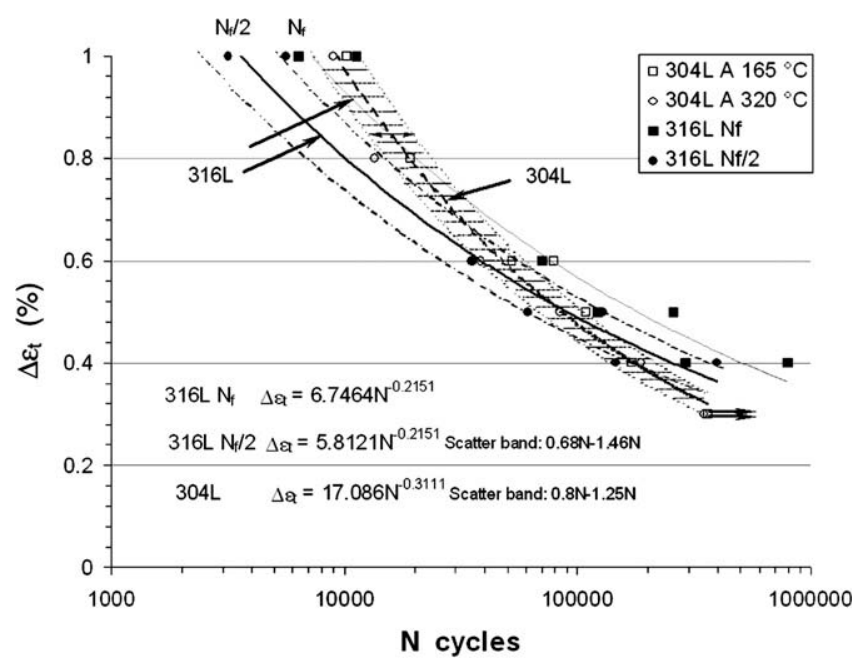

Fig. A1. Comparison between Type 304L and 316L steels used for SPLASH and FAT3D, respectively - strain variation as a function of number of cycles for LCF tests. 304L LCF tests correspond to 165 and $320^{\circ} \mathrm{C}$, 316L LCF tests corresponds to Nf/2 at room temperature as justified in Fig. 5 Part I.

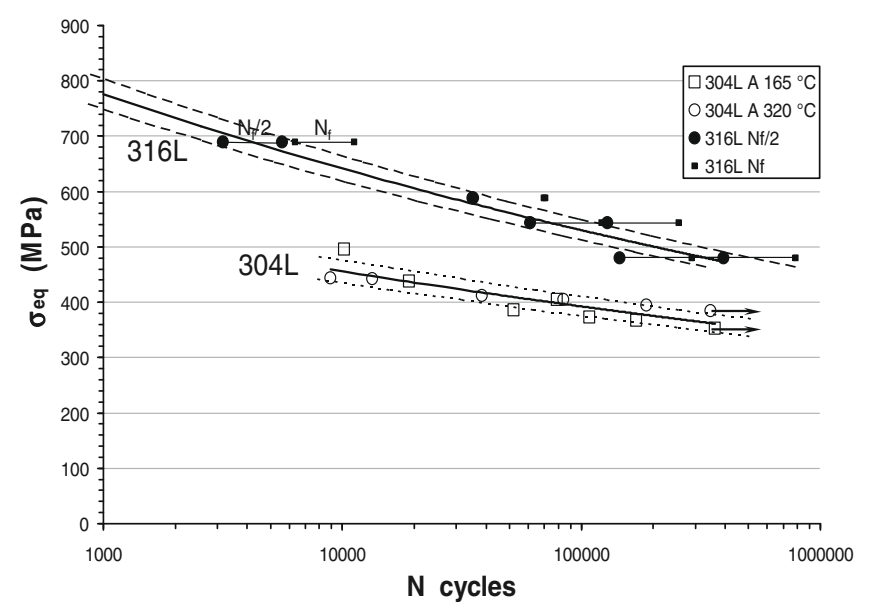

Fig. A2. Comparison between Type 304L and 316LN steels used for SPLASH and FAT3D, respectively - stabilized stress at half life. 304L LCF tests correspond to 165 and $320^{\circ} \mathrm{C}, 316 \mathrm{~L} \mathrm{LCF}$ tests corresponds to $N_{\mathrm{f}} / 2$ at room temperature as justified in Fig. 5 Part I.

comparable with both $316 \mathrm{~L}$ and $304 \mathrm{~L}$ steels when strain range is less than $0.6 \%$.

Regarding stabilized stress, which corresponds to stress reached at half-life, a significant difference is observed between the two steels (Fig. A2). Type 304L steel appears to have a more ductile behaviour.

\section{Appendix B. Details on the parameter $\alpha$ used in the criterion proposed by S. Amiable ("Ecole Polytechnique)}

Traction-torsion tests performed by Itoh [49] are used to determine the parameter $\alpha$. Fig. B1 presents the traction-torsion loading paths. Fig. B2 highlights the good agreement between data issued from SPLASH, Itoh and push-pull tests. 


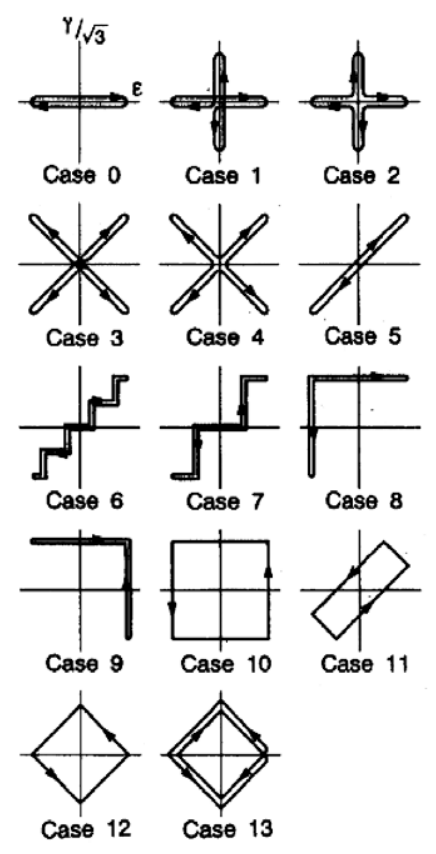

Fig. B1. Traction-torsion tests performed by Itoh [49] with 13 loading paths.

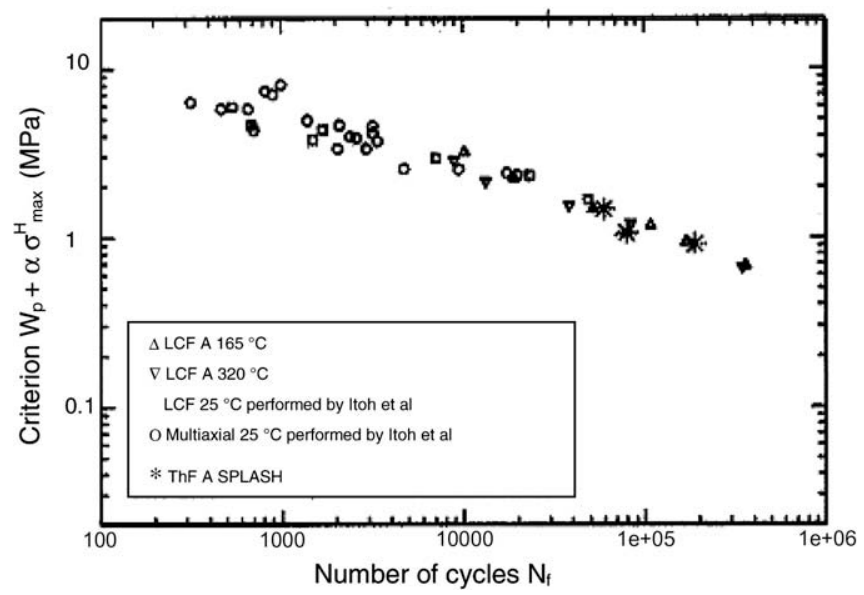

Fig. B2. Criion based on energy proposed in S. Amiable's PhD Thesis. Value of $\alpha=0.007$ is determined from push-pull tests, traction-torsion tests performed by Itoh [49] and SPLASH thermal fatigue tests.

\section{References}

[1] Faidy C, Le Courtois T, de Fraguier E, Le Duff JA, Le François A, Dechelotte J Thermal fatigue in French RHR system. In: International conference on fatigue of reactor components, July 31-August 2 2000, Napa, CA, USA.

[2] Remy L. Recent development in thermal Fatigue. Mech Eng Publ 1990: 353-77.

[3] Haddar N. In: French, fatigue thermique d'un acier inoxydable austénitique 304L, PhD thesis, Ecole Supérieure des Mines de Paris, 2003.

[4] Remy L, Koster A, Chataigner E, Bickard A. Thermal-mechanical fatigue and the modelling of material behaviour under thermal transients. In: Thermomechanical behavior of materials: proceedings of the symposium, Norfolk, USA, 4-5 November 1998, 3rd vol; 2000. p. 223-38.

[5] Evans WJ, Screech JE, Williams SJ. Thermo-mechanical and fracture of INCO718. Int J Fatigue 2008;30(2):257-67.

[6] Sehitoglu $\mathrm{H}$. Thermal and thermomechanical fatigue of structural alloys. Fracture mechanics, damage tolerance and life assessment. Materials Park (OH): ASM International; 1996. p. 527-56.
[7] Fujino M, Taira S. Effect of thermal cycling on low cycle fatigue of steels and grain boundary sliding characteristics. In: Proceedings of ICM3, vol. 2; 1979. p. 49-58.

[8] Moulin D, Roche RL. Correction of the poisson effect in the elastic analysis of low cycle Fatigue. Int J Pres Vessels Piping 1985;19:213-33.

[9] Suresh S. Fatigue of materials Cambridge, solid state science series. 1st ed. Cambridge University Press; 1991.

[10] Robertson C, Fivel MC, Fissolo A. Dislocation substructure in 316L stainless steel under thermal fatigue up to $650 \mathrm{~K}$. Mater Sci Eng A 2001;315(1-2): 47-57.

[11] Depres C, Robertson C, Fivel MC. Crack initiation in fatigue: experiments and three-dimensional dislocation simulations. Mater Sci Eng A 2004;A 387-389:288-91.

[12] Bernasconi A. Efficient algorithms for calculation of shear stress amplitude and amplitude of the second invariant of the stress deviator in fatigue criteria applications. Int J Fatigue (UK) 2002;24:649-57.

[13] Papadopoulos IV, Davoli P, Gorla C, Filippini M, Bernasconi A. A comparative study of multiaxial high-cycle fatigue criteria for metals. Int J Fatigue (UK) 1997:19:219-35.

[14] Morel F. A critical plane fatigue model applied to out of phase bending and torsion loads conditions. Fat Fract Eng Mater Struct 2001;24:153-64.

[15] Henaff G, Morel F. Fatigue des structures. Endurance, critères de dimensionnement, propagation de fissures, rupture. Edition Ellipse 2005.

[16] Sines G. Behaviour of Metals under complex stresses. In: Sines G, Weisman JL, editors. Metal fatigue. New York: Mc Graw Hill; 1959. p. 145-69.

[17] Lemaitre J, Chaboche JL. Mécanique des matériaux solides. Dunod; 1998.

[18] Brand A, Flavenot JF, Gregoire R, Tournier C. Données technologique sur la fatigue, Publications 1999, CETIM.

[19] Crossland B. Torsion testing machines. In: Developments in materials testing machine design, symposium. London (Manchester, England): Institute of Mechanical Engineering; 1965. p. 85-96.

[20] Dang Van K. On the resistance of metals to fatigue. Sci Tech l'Armement (Mémorial l'Artillerie Française) 1973;47(3):647-722.

[21] Papadopoulos IV. Fatigue polycyclique des métaux. Une nouvelle approche. PhD Thesis Ecole Nationale des Ponts et Chaussés 1987, Paris.

[22] Matake T. An explanation on fatigue limit under combined stress. Bull JSME 1977;20:257-63.

[23] Findley WN. A theory for the effect of mean stress on fatigue of metals under combined torsion and axial load or bending. J Eng Ind, Trans ASME 1959;81:301-6.

[24] McDiarmid DL. A general criterion for high cycle multiaxial fatigue failure. Fat Fract Eng Mater Struct 1991;14(4):429-53.

[25] Coffin LF, Schenectady NY. A study of the effects of cyclic thermal stresses on a ductile metal. Trans ASME 1954;76:931-50.

[26] Manson SS, Halford GR. Multiaxial low cycle fatigue of Type 304 stainless steel. J Eng Mater Tech 1977;July:283-5.

[27] Bathias CJ, Ba JP. La fatigue des matériaux et des structures. 2nd ed. Paris: Hermes; 1997.

[28] Davis EA, Connelly FM. Stress distribution and plastic deformation in rotating cylinders of strain hardening materials. J Appl Mech, Trans ASME 1959;81:2-30.

[29] Zamrik SY, Mirdamadi M, Davis DC. A proposed model for biaxial fatigue analysis 11 using the triaxiality factor concept. Advances in Multiaxial Fatigue. ASTM STP 1191; 1993. p. 85-106.

[30] Manjoine MJ. Damage and failure at elevated temperature. J Press Ves Tech 1983;105:58-62.

[31] Brown MW, Miller KJ. Two decades of progress in the assessment of multiaxial low cycle fatigue. Low cycle fatigue and life prediction. ASTM STP, 770 1982, 1982. p. 482-99.

[32] Socie DF, Waill LA, Dittmer DF. Biaxial fatigue on Inconel 718 including mean 18 stress effects. Multiaxial fatigue; ASTM STP 853, 1985. p. 463-81.

[33] Fatemi A, Socie DF. A critical plane approach to multiaxial fatigue damage including out of phase loading. Fat Fract Eng Mater Struct 1988;11(3): 149-65.

[34] Park J, Nelson D. Evaluation of an energy-based approach and a critical plane approach for predicting constant amplitude multiaxial fatigue life. Int J Fatigue (UK) $2000 ; 22(1): 23-9$.

[35] Charkaluk E, Constantinescu EA. An energetic approach in thermomechanical fatigue for silicon molybdenum cast iron. Mater High Temp (UK) 2000;17(3): 373-80.

[36] Wang Y-Y, Yao W-X. Evaluation and comparison of several multiaxial fatigue criteria. Int J Fatigue 2004;26(1):17-25.

[37] Amiable S, Chapuliot S, Constantinescu A, Fissolo A. Prédiction de durée de vie sous chargement de fatigue thermique. 17ème Congrès Français de Mécanique, Troyes, France, 2005.

[38] Amiable S, Chapuliot S, Constantinescu A, Fissolo A. A comparison of lifetime prediction methods for a thermal fatigue experiment. Int $\mathrm{J}$ Fatigue 2006;28(7):692-706.

[39] Amiable S. Prédiction de durée de vie des structures sous chargement de fatigue thermique. PhD thesis, Université de Versailles, 2006.

[40] Smith KN, Topper TH, Watson P. A stress-strain function for the fatigue of metals. J Mater 1970;5:767-78.

[41] Liu KC. A method based on virtual strain energy parameters for multiaxial fatigue life prediction. Advances in multiaxial fatigue. ASTM STP 1191, 1993. p. $67-84$. 
[42] Glinka G, Shen G, Plumtree A. A multiaxial fatigue strain energy density parameter related to the critical plane. Fat Fract Eng Mater Struct (UK) 1995;18(1):37-46.

[43] Varvani-Farahani A. A new energy critical plane parameter for fatigue life assessment of various metallic materials subjected to in phase and out of phase multiaxial fatigue loading conditions. Int J Fatigue 2000;22: 295-305.

[44] Socie D. Critical plane approaches for multiaxial fatigue damage assessment. Advances in multiaxial fatigue. Mc Dowell/ Ellis: ASTM STP 1191; 1993. p. 7-36.

[45] Doquet V. PhD thesis, of Ecole Nationale Supérieure des Mines de Paris, 1989.

[46] Ancelet O. Etude de l'amorçage et de la propagation des fissures sous chargement cyclique, CEA Report R-6109, PhD thesis, University of Poitiers, France, 2006.

[47] Ancelet O, Chapuliot S, Hennaf G, Marie S. Development of a test for the analysis of the harmfulness of a 3D thermal fatigue loadings in tubes. Int J Fatigue 2007;29:549-64.

[48] Halford GR. The energy required for fatigue (plastic strain energy required for fatigue in ferrous and nonferrous metals). J Mater 1966;1:3-18.

[49] Itoh T, Sakane M, Ohnami M, Socie D. Nonproportional low cycle fatigue criterion for type 304 stainless steel. J Eng Mater Tech, Trans ASME 1995;117(3):285-92.

[50] RCC-MR French code, Association Française pour les Règles de conception et de construction des Chaudières Electro-Nucléaires, Edition 2002.

[51] Zhu D, Fox DS, Miller RA. 2000. <http://www.grc.nasa.gov/WWW/RT2000/ 5000/5100C-zhu.html>.

[52] Cote PJ, Lee SL, Todaro ME, Kendall G. Application of laser pulse heating to simulate thermomechanical damage at gun bore surfaces. J Press Ves Tech 2003;125(3):335-41.

[53] Long SG, Zhou YC. Thermal fatigue of particle reinforced metal-matrix composite by laser heating and mechanical load. Comp Sci Tech 2005;65:1391-400.
54] Oyoma T, Yamamoto A, Mohri K, Saito M. Crack propagation behavior by thermal fatigue around DSCu/SS316 HIP bonded interface. Fusion Eng Des 2005;75-79:423-8.

[55] Douglas L, Jones PK, Poulose H, Liebowitz. Effect of biaxial loads on the static and fatigue properties of composite materials. Multiaxial fatigue, ASTM STP 853, 1985. p. 413-27.

[56] Sermage JP, Lemaitre J, Desmorat R. Multiaxial, creep-fatigue under anisothermal conditions. Fat Fract Eng Mater Struct 2000;23(3):241-53.

[57] Zouani A, Bui-Quoc T, Bernard M. Optimal design of a disk-shaped specimen for biaxial-tensile fatigue. J Test Evaluat 1996;24(5):287-94.

[58] Riemelmoser FO, Pippan R. Consideration of the mechanical behaviour of small fatigue cracks. Int J Fract 2002;118:251-70.

[59] Riemelmoser FO, Gumbush P, Pippan R. Plastic deformation at short edge cracks under fatigue loading. Eng Fract Mech 2000;66:357-74.

[60] Cipière MF, Le Duff JA. Influence of surface condition and weld local geometry. Weld World 2002;46(1-2):23-7.

[61] Taheri S. High cycle thermal crazing, a phenomena related to the structure. Méc Ind 2005;6:331-5.

[62] Miner MA. Cumulative damage in fatigue. J Appl Mech 1945;12:159-64.

[63] Cipière MF, Le Duff JA. Thermal fatigue experience in French piping. In: International institute of welding, 2001, Document no. XIII - 1891-01, Lubjana.

[64] Gourdin C, Magnaud JP, Chapuliot S, Payen T, Monavon A. Hydro-thermal analysis of thermal fatigue in a mixing tee. Nucl Eng Des 2005;235: 575-96.

[65] Braillard O, Jamy Y, Balmigere G. Thermal load determination in the mixing tee impacted by a turbulent flow generated by two fluids at large gap of temperature, Icone 13 - 50361. In: 13th International conference on nuclear engineering, 2005, Beijing, China. 